Article

\title{
Temporal Aspects in Emission Accounting-Case Study of Agriculture Sector
}

\author{
Lelde Timma $^{1, *} \mathbb{0}$, Elina Dace ${ }^{2,3}$ a and Marie Trydeman Knudsen ${ }^{1}$ \\ 1 Department of Agroecology, Aarhus University, Blichers Allé 20, DK-8830 Tjele, Denmark; \\ mariet.knudsen@agro.au.dk \\ 2 Institute of Microbiology and Biotechnology, University of Latvia, 1 Jelgavas Street, LV1004 Riga, Latvia; \\ elina.dace@lu.lv \\ 3 Research Department, Riga Stradins University, 16 Dzirciema Street, LV1007 Riga, Latvia \\ * Correspondence: lelde.timma@agro.au.dk
}

Received: 15 January 2020; Accepted: 10 February 2020; Published: 12 February 2020

check for

\begin{abstract}
Complex relations link climate change and agriculture. The vast majority of the studies that are looking into the quantification of the climate impacts use the Global Warming Potential (GWP) for a 100-year time horizon (GWP100) as the default metrics. The GWP, including the Bern Carbon Cycle Model (BCCM), was proposed as an alternative method to take into consideration the amount and time of emission, and the fraction of emissions that remained in the atmosphere from previous emission periods. Thus, this study aims to compare two methods for GHG emission accounting from the agriculture sector: the constant GWP100 and the time dynamic GWP100 horizon obtained by using the BCCM to find whether the obtained results will lead to similar or contradicting conclusions. Also, the effect of global temperature potential (GTP) of the studied system is summarized. The results show that the application of the $\mathrm{BCCM}$ would facilitate finding more efficient mitigation options for various pollutants and analyze various parts of the climate response system at a specific time in the future (amount of particular pollutants, temperature change potential). Moreover, analyze different solutions for reaching the emission mitigation targets at regional, national, or global levels.
\end{abstract}

Keywords: climate modelling; climate change; climate policy; emission accounting; global warming potential; global temperature change potential; greenhouse gas emissions; impulse response function; Bern Carbon Cycle model; climate impacts of agriculture system

\section{Introduction}

The growing global population leads to an increasing need for resources-food, energy, and materials. This expanding demand forces the shift from a fossil-based linear economy to a sustainable biobased economy. Bioeconomy demands biological feedstock that has the potential to generate a spectrum of bio-based products by involving multidisciplinary areas of science, management, and engineering [1]. Agriculture is the primary supply of nutrition and bioenergy and a substantial contributor to the bioeconomy. Yet, agriculture is also linked with environmental, economic, and social aspects of climate change. For example, climate change affects the productivity of the agriculture sector, and thus change in the agricultural practices feedback to the greenhouse gas (GHG) balance. Therefore, climate change and agriculture are linked by complex relations, which can be difficult to define or measure [2].

The vast majority of the studies that are looking into the quantification of the climate impacts use the Global Warming Potential (GWP) for a 100-year time horizon as the default metrics. Since the development of GWP metric in the early nineties, there have been updates only on the numerical value of this metric, rather than the development of the assessment methodology itself [3]. 
The use of GWP is an accepted measure within the Kyoto Protocol to the United Nations Framework Convention on Climate Change as a measure to weigh the impact of climate due to the emissions of GHGs. Although the use of GWP has received various criticism due to underlying assumptions, it became widely accepted measure because of transparency and ease of use [4]. There were numerous alternative methods developed to substitute use of GWP, such as Global Temperature Change Potential (GTP) by Shine et al. [4], Global Warming Potential using cumulative CO2 forcing-equivalent (GWP*) by Allen et al. [5] and other normalized point and integration metrics (see the review by Levasseur et al. [6]). Current studies on climate science show that processes occurring in the natural environment sometimes cannot be reasonably well quantified using a single value for measuring the impact created in the 100-year perspective. This quantification using a single value cannot be done due to the non-linear nature of the emission dissipation in various environments that leads to spatial and temporal heterogeneities. Misinterpretation of these effects can lead to policy decisions that underestimate the impacts of the emissions with a short lifetime and with a dominating local pollution effect. An example of this phenomenon is given in the thesis work by Shimako [7] and published in the paper by Shimako et al. [8]. This work shows that the same amount of emissions might have different influence if the timing of emissions is considered. Another limitation of GWP is that it estimates the forcing of the climate but does not characterize the impact of climate dynamics. Although climate dynamics are included in the global temperature change potentials (GTPs), they are not intended to illustrate the influence of radiative forcing and enable a qualitative interpretation of causes [9].

The GWP, including the Bern Carbon Cycle Model (BCCM), was proposed as an alternative method to take into consideration both amount and time of emission, as well as the fraction of emissions remaining in the atmosphere from previous emission periods. Furthermore, BCCM considers the effect of GHG emissions estimated as a continuous pattern that handles removals (via sinks) and addition of new emissions to the "stock" of the atmosphere hence also considering the climate system response to emissions.

Thus, this study aims to compare two methods for GHG emission accounting from the agriculture sector. Firstly, the constant GWP values for a 100-year time horizon (GWP100) and, secondly, the time dynamic GWP values for a 100-year time horizon obtained by using the BCCM to find whether the obtained results will lead to similar or contradicting conclusions. Also, the effect of global temperature potential (GTP) of the studied system is summarized.

The agriculture sector is the world's leading source of non- $\mathrm{CO}_{2} \mathrm{GHG}$ emissions and the secondlargest GHGs emission source overall. On the global scale, in 2010, the non- $\mathrm{CO}_{2} \mathrm{GHG}$ emissions from agriculture accounted for $10-12 \%$ of the total annual anthropogenic emissions or 5.2-5.8 $\mathrm{Gt} \mathrm{CO}_{2}$ eq. [10]. The same share of the GHGs emissions from agriculture is also evident in the European Union (EU), where $0.442 \mathrm{Gt} \mathrm{CO}_{2}$ eq. originated from agriculture that corresponds to around $10 \%$ of the total annual GHG emissions in the EU. Based on the EU strategy for a low-carbon economy by 2050 [11], non- $\mathrm{CO}_{2}$ GHG emissions or GHG emissions not covered by the EU Emissions Trading Scheme (non-ETS) should be cut down by $30 \%$ in the comparison to the emission in 2005 [12]. Thus, these emission reductions should also substantially relay on the emission cutbacks in the agriculture sector. Therefore, a lot of research is put into the evaluation of emission mitigation potential in the EU Member states, including a detailed analysis of the agriculture sector $[13,14]$.

\section{Materials and Methods}

In this study, we compare the method for "traditionally" accounted for GHG emissions and the GWP method that is used in the BCCM. By "traditional" accounting, we mean the use of GWP and multiplying this value of GWP with the corresponding amount of GHG emission of the specific pollutant, given in IPCC guidelines for national GHG inventories and Section 2.1 of this article. As a method using the BCCM, we refer to the use of impulse response function and decay of pulse emissions, which is also covered in the latest (fifth) IPCC assessment report [15] given in detail in Section 2.2 of this article. 


\subsection{Method Used in IPCC Guidelines for the National GHG Inventories}

The Intergovernmental Panel on Climate Change (IPCC) has created an internationally agreed methodology for the assessment of GHG emissions from numerous sectors, including agriculture [16]. The assessed GHG emissions (inventories) are used for approximate anthropogenic emissions by sources and removals by sinks of GHGs. Each year, countries, including the EU Member States, submit individual reports on the inventory of national emissions to the United Nations Framework Convention on Climate Change (UNFCCC). These reports are used to account for the current state of the GHG emissions, see global trends, and make forecasts. Moreover, IPCC has accomplished that based on the reports, governments take action towards the mitigation of climate change [2].

The GHGs included in the IPCC guidelines are carbon dioxide $\left(\mathrm{CO}_{2}\right)$, nitrous oxide $\left(\mathrm{N}_{2} \mathrm{O}\right)$, methane $\left(\mathrm{CH}_{4}\right)$, and fluorinated gases (HFCs, PFCs, and SF6). To quantify, compare, and analyze the emissions, promote mitigation options, and design sustainable policy strategies, a default emission metric, $\mathrm{CO}_{2}$ equivalent (eq.), has been developed. The $\mathrm{CO}_{2}$ eq. is obtained by multiplying the estimated amount of non- $\mathrm{CO}_{2}$ GHG emission (component i) by a coefficient of that specific non- $\mathrm{CO}_{2}$ emission for a fixed time horizon (usually 20 or 100 years) and summing the obtained individual $\mathrm{CO}_{2}$ eq. values into an aggregated emission metric. The coefficient used is known as the global warming potential (GWP) - " an index, based on radiative properties of greenhouse gases, measuring the radiative forcing following a pulse emission of a unit mass of a given greenhouse gas in the present-day atmosphere integrated over a chosen time horizon, relative to that of $\mathrm{CO}_{2}{ }^{\prime \prime}$ [15].

Based on new scientific and technical knowledge, the guidelines have had two major revisions since their 1996-version: "2006 IPCC Guidelines for National Greenhouse Gas Inventories" and the recently adopted "2019 Refinement to the 2006 IPCC Guidelines for National Greenhouse Gas Inventories". As a result of refinement, new sources, and pollutants, and updates to the previously published methods, have been included in the guidelines. Also, the numeric value of the global warming potential has been updated since its first introduction in the early nineties (see Table 1). Changes in the GWP value have been made due to improved scientific knowledge and updated estimates of the energy absorption, lifetime, impulse response functions. Estimates on impulse response functions or radiative efficiencies of GHGs vary because of changing atmospheric concentrations of GHGs that result in a change in the energy absorption of one additional ton of a gas relative to another [15]. Since GWP of $\mathrm{CO}_{2}$ is used as a reference, GWP of $\mathrm{CO}_{2}$ equals one and remains constant regardless of the used time frame. Therefore, any parameter adjustments for $\mathrm{CO}_{2}$ will affect all results of the assessments done for other GHGs [15].

Table 1. Global Warming Potential (GWP) values since the first assessment report, unitless [15,17].

\begin{tabular}{cccccccc}
\hline Time Horizon & Gas & IPCC 1990 & IPCC 1996 & IPCC 2000 & IPCC 2006 & IPCC 2013 & IPCC 2013 \\
\hline 20 years & $\mathrm{CH}_{4}$ & 63 & 56 & 62 & 72 & 84 & 86 \\
20 years & $\mathrm{N}_{2} \mathrm{O}$ & 270 & 280 & 275 & 289 & 264 & 268 \\
100 years & $\mathrm{CH}_{4}$ & 21 & 21 & 23 & 25 & 28 & 34 \\
100 years & $\mathrm{N} 2 \mathrm{O}$ & 290 & 310 & 296 & 298 & 265 & 298 \\
\hline \multicolumn{7}{r}{ With climate-carbon feedbacks [15]. }
\end{tabular}

The selection of time horizon has a substantial influence on the GWP values; hence, the estimated contribution to the total emissions by the component $i$ [15]. The majority of studies and agreements use the 100-year time horizon. Also, the Kyoto Protocol and the Paris Agreement are based on GWPs from pulse emissions over a 100-year time horizon. And, indeed, for many objectives, the 100-year time horizon is applicable, especially taking into account the long-term effects of GHG emissions and the need for long-term modelling of future temperatures. Yet, the 20-year time horizon might be a more appropriate choice for regional/national strategies or mid-term modelling applications as their focus typically is on a much shorter time frame [18]. In addition, tropospheric temperatures that are more relevant for regional/national decision makers may show more rapid changes in radiative forcing, which creates a situation when the choice of a short time horizon is more fitting [19]. 
Although the use of the GWP is considered a relatively simple and easy-to-use method, in recent years, it has received some criticism. For example, Peters et al. [20] and Ledgard and Reisinger [21] point to the contrary outcomes that frequently are the result of a negligent and only implicit value judgment of the time horizon to be selected. Joos et al. [22] and Tanaka et al. [23] emphasize the importance of the proper selection of the time horizon in the determination of metrics variability, especially for the GWP value given to gases with a relatively short lifetime (e.g., $\mathrm{CH}_{4}$ ) compared to gases with long lifetimes (e.g., $\mathrm{CH}_{2}$ ). Cherubini et al. [3] state that uses of GWP values omits impacts from short-term gases and biophysical factors arising from changes in land cover, as well as overlooks the temporal and spatial heterogeneities of the climate system response to GHG emissions. Also, Skytt et al. [18] state that with GWP, a difficulty exists on how to value $\mathrm{CH}_{4}$ emissions with $\mathrm{CO}_{2}$ and that the use of GWP values provides "static" information expressed as the radiative forcing potential at a specific time horizon. Finally, the phenomenon of overall acceptance and use of the GWP as a metric for GHG emission accounting by policy developers and scientific community is surprising, considering that since its first introduction by the IPCC in the first assessment report [17], it has had no direct estimation of any climate system responses or direct link to policy goals (Myhre et al. [15]; Cherubini et al. [3]). Hence, the potential use of alternative methods have been proposed and extensively discussed in the literature (see, e.g., Cherubini et al. [3], Levasseur et al. [6], and Skytt et al. [18]). In Section 2.2., a method based on the BCCM is presented as an alternative approach for estimating the temporal effects of GHGs on the climate system.

\subsection{Method Used in the Bern Carbon Cycle Model (BCCM)}

The BCCM describes the decay pattern of GHGs in the atmosphere [24], i.e., both the amount and time of emission are considered, as well as the fraction of emissions remaining in the atmosphere from previous emission periods. Moreover, not constant values are taken (as 20 or 100 years), but the effect of emissions is estimated as a continuous pattern that considers removals (via sinks) and addition of new emissions to the "stock" of the atmosphere, hence also considering the climate system response to emissions. The BCCM targets several aspects of the climate impact cause-effect loop (see Figure 1).

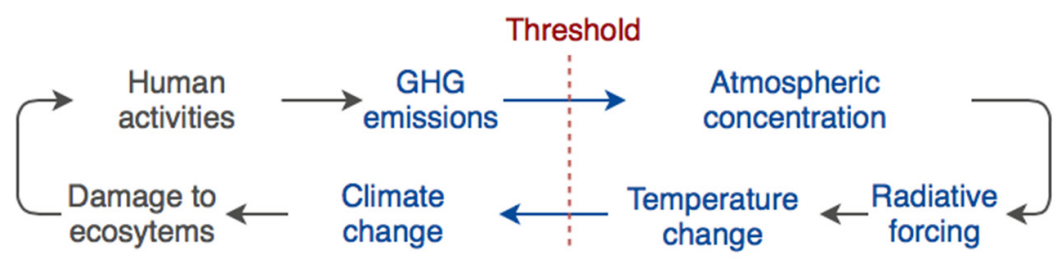

Figure 1. The cause-effect loop of greenhouse gas (GHG) emissions and climate change in blue given segments of the loop that are studied in this article. Figure adapted from Fuglestvedt et al. [25].

The application of climate impulse response models for GHG emissions has been developed by Levasseur et al. [26] and Joos et al. [22]. The impulse response function (IRFs) are usually used in two ways: to describe the decay of atmospheric concentration of pulse emissions or to express global temperature changes due to pulse radiative forcing [27]. The effect of IRF inclusion in the climate response model is graphically represented in Figure 2.
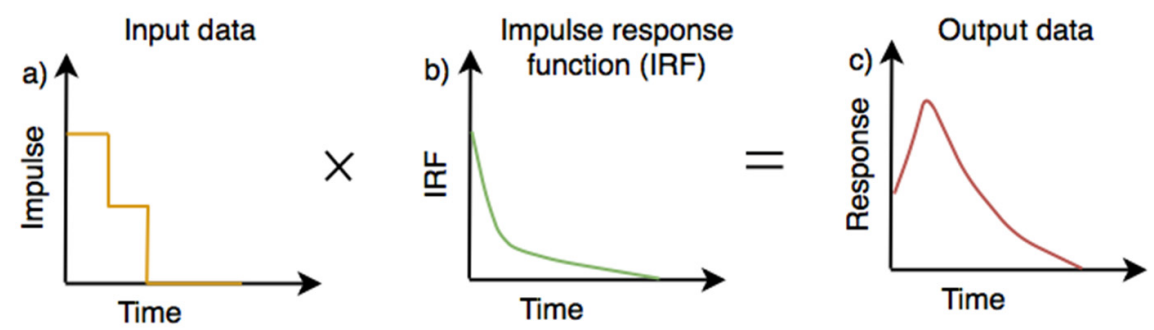

Figure 2. Conversion of input data using impulse response function (IRF), adapted from Shimako [7]. 
Pulse emission is the emission of $1 \mathrm{~kg}$ of pollutants at the time $t=0$. When pulse emission is released to the atmosphere, it serves as an impulse to the complex set of behavioural reactions that occur in climate systems.

These climate responses are condensed into simplified mathematical models that use impulse response function $(I R F)$ [27] given as a response of the temporal temperature to a sudden unit pulse of radiative forcing [28],

$$
y_{i}(t)=\int_{0}^{t} x_{i}(t) I R F_{i}(t) d t
$$

where $y_{i}(t)$ is the environmental impact of the pollutant $i$ at the time step $t, x$ is the emitted amount of the pollutant $i$, and $I R F_{i}$ is the impulse response function of the pollutant $i$ [29],

$$
\operatorname{AGWP}_{i}(H)=\int_{0}^{t} R F_{i}(t) d t=A_{i} R_{i}
$$

where $A G W P_{i}$ is the absolute global warming potential of pollutant $i\left(\mathrm{~W} \cdot \mathrm{m}^{-2} \mathrm{~kg}^{-1} \cdot \mathrm{year}\right), R F_{i}$ is the radiative forcing occurring due to a pulse emission of pollutant $i$ emitted to the atmosphere at time horizon $H\left(\mathrm{~W} \cdot \mathrm{m}^{-2}\right) . R F$ is the function of specific radiative forcing $\left(A_{i}, \mathrm{~W} \cdot \mathrm{m}^{-2} \mathrm{~kg}^{-1}\right)$ - the ability to increase $R F$ when the unit of the specific pollutant's $i$ mass increases in the atmosphere (see Table 2 for numerical values), and the fraction of pollutant's mass remaining in the atmosphere after the pulse emission of the pollutant $i\left(R_{i}\right)$. The fraction of pollutant's $i$ mass remaining in the atmosphere at the time moment $t\left(R_{i}(t)\right)$ is given as a simple exponential decay function:

$$
R_{i}(t)=\exp \left(-t / \tau_{i}\right)
$$

where $\tau_{i}$ is the time needed for the pulse emission of pollutant $i$ to converge to zero concentration, known as perturbation lifetime (years) [22], for $\mathrm{CO}_{2}, \mathrm{CH}_{4}$, and $\mathrm{N}_{2} \mathrm{O}$ emissions, the pattern of $R$ is substantially different over a 1000 years' perspective (see Figure 3 ).

Table 2. Specific radiative forcing $\left(A_{i}\right)$, perturbation lifetimes $\left(\tau_{i}\right)$, and parameter $a_{i}$ values for the calculation of the pollutant's fraction remaining in the atmosphere $\left(R_{i}\right)[3,15,22,29]$.

\begin{tabular}{cccc}
\hline \multirow{2}{*}{ Pollutant } & \multicolumn{3}{c}{ Constants } \\
\cline { 2 - 4 } & $A_{i}, \mathbf{W} \cdot \mathbf{m}^{-\mathbf{2}} \mathbf{k g}^{-\mathbf{1}}$ & $\boldsymbol{\tau}_{\boldsymbol{i}}$, Years & $\boldsymbol{a}_{\boldsymbol{i}}$, Unitless \\
\hline $\mathrm{CH}_{4}$ & $1.82 \cdot 10^{-13}$ & 12.4 & - \\
$\mathrm{N}_{2} \mathrm{O}$ & $3.88 \cdot 10^{-13}$ & 121.0 & - \\
& & - & $0.2173, a_{0}$ \\
$\mathrm{CO}_{2}$ & & $394.40, \tau_{1}$ & $0.2240, a_{1}$ \\
& $1.7517 \cdot 10^{-15}$ & $36.54, \tau_{2}$ & $0.2824, a_{2}$ \\
& & $4.304, \tau_{3}$ & $0.2763, a_{3}$ \\
\hline
\end{tabular}

Most of the pollutants follow single exponential decay, while for the $\mathrm{CO}_{2}$, the behaviour is given with more complex equations [22]. Hence, also the fraction of various GHGs remaining in the air varies by nature. As seen in Figure 3, for $\mathrm{CH}_{4}$, the decay is much faster, while almost a quarter of the $\mathrm{CO}_{2}$ emitted in the year 0 is still present in the atmosphere even after 1000 years.

While the perturbation lifetime and specific radiative forcing are known constants for some of the emissions, such as $\mathrm{CO}_{2}, \mathrm{CH}_{4}, \mathrm{~N}_{2} \mathrm{O}$, and others (see Table 2 for numerical values). The fraction of $\mathrm{CO}_{2}$ pulse emission remaining in the atmosphere cannot be represented by a single constant and a simple exponential decay function, as in the case of $\mathrm{CH}_{4}$ and $\mathrm{N}_{2} \mathrm{O}$. The fraction of $\mathrm{CO}_{2}$ pulse emission remaining in the atmosphere follows approximation by a sum of exponential functions:

$$
R_{\mathrm{CO}_{2}}(t)=a_{0}+\sum_{i=1}^{3} a_{i} \exp \left(-t / \tau_{i}\right)
$$


Global warming potential for pollutant $i$ at time $t\left(G W P_{i}(t)\right)$ is calculated by referring absolute global warming potential of the pollutant $i(A G W P i)$, to the $A G W P$ of the reference gas, usually $\mathrm{CO}_{2}$, and integrating it over time period $t$ :

$$
G W P_{i}(t)=A G W P_{i}(t) / A G W P_{\mathrm{CO}_{2}}(t)=\int_{0}^{t} R F_{i}(t) d t / \int_{0}^{t} R F_{\mathrm{CO}_{2}}(t) d t
$$

The change of normalized GWP values and absolute GWP values over 100 years in the case of pulse emissions of $\mathrm{CO}_{2}, \mathrm{~N}_{2} \mathrm{O}$, and $\mathrm{CH}_{4}$ are given in Figures 4 and 5, respectively.

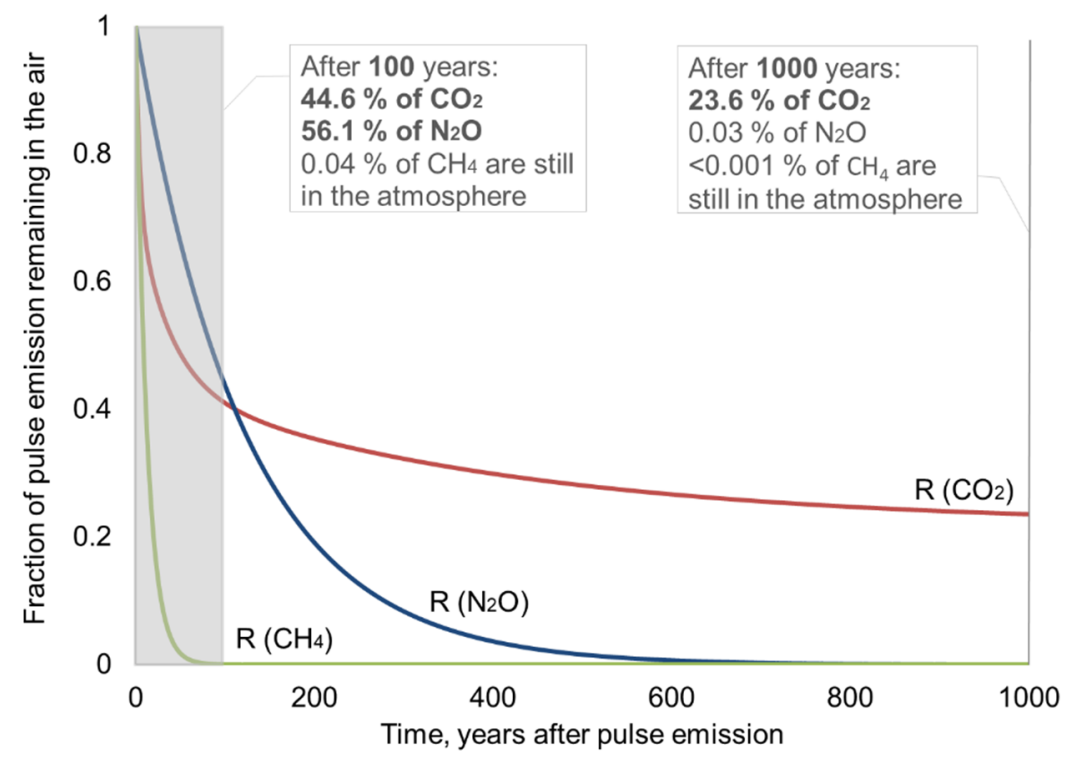

Figure 3. The fraction of pulse emissions at year zero remaining for greenhouse gas emissions of $\mathrm{CO}_{2}$, $\mathrm{N}_{2} \mathrm{O}$, and $\mathrm{CH}_{4}$ in 1000 years' time frame.

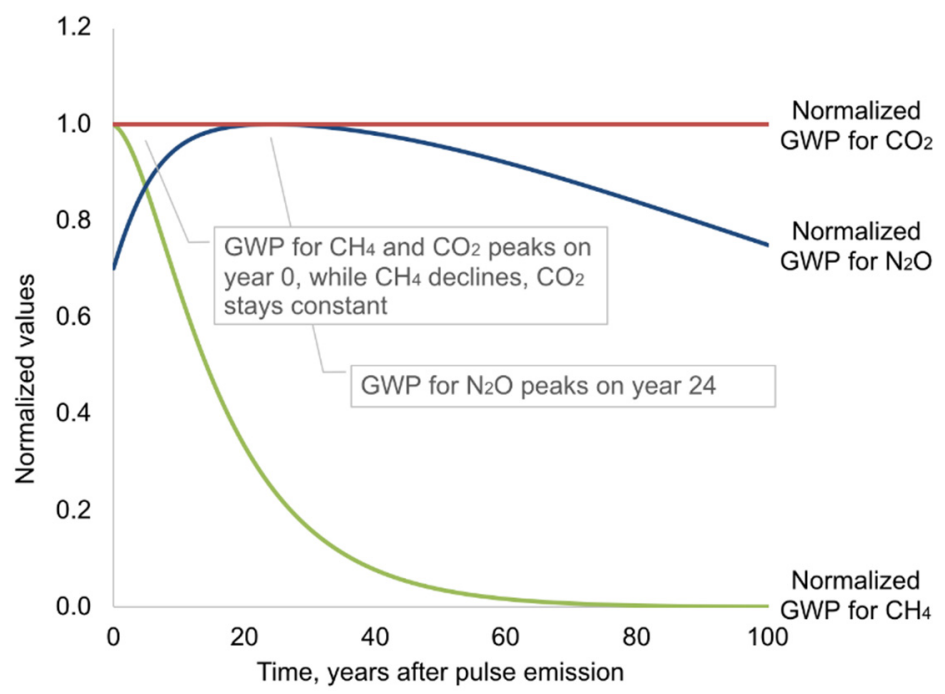

Figure 4. Normalized GWP values as a response to emission of $\mathrm{CO}_{2}, \mathrm{~N}_{2} \mathrm{O}$, and $\mathrm{CH}_{4}$ at year zero. The values are normalized to the maximum value of the corresponding GWP of each gas, unitless.

As can be seen in Figures 4 and 5, the trendlines for the emissions of $\mathrm{CH}_{4}$ and $\mathrm{N}_{2} \mathrm{O}$ are both of different natures and different magnitude, while $\mathrm{CO}_{2}$ constant values of 1 are assumed. 


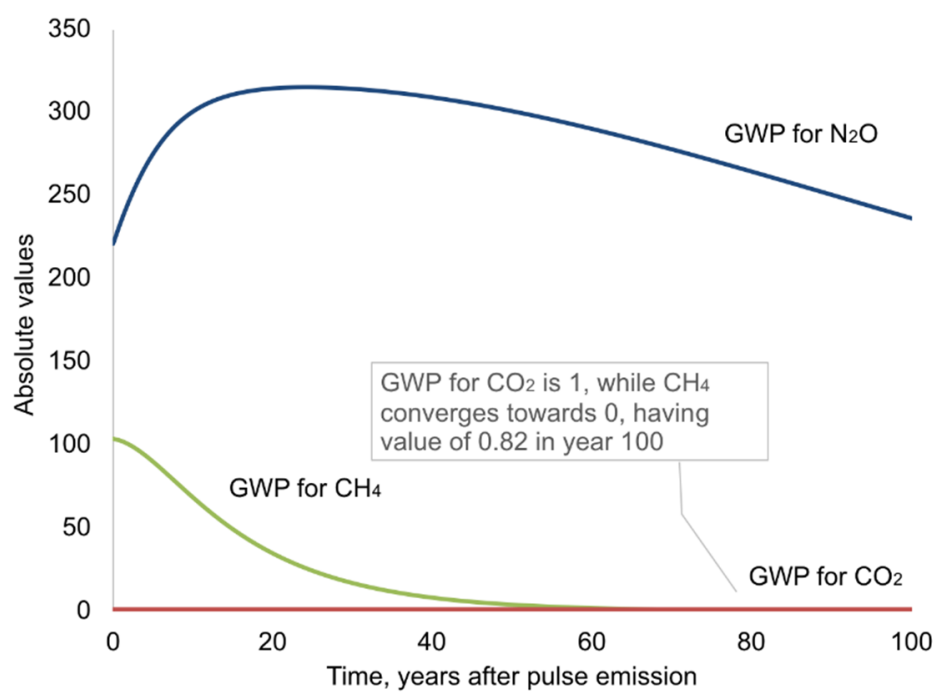

Figure 5. Absolute GWP values as a response to emission of $\mathrm{CO}_{2}, \mathrm{~N}_{2} \mathrm{O}$, and $\mathrm{CH}_{4}$ at year zero, unitless.

Global temperature potential for pollutant $i$ at time $t\left(G T P_{i}(t)\right)$ is calculated by referring absolute global temperature potential of the pollutant $i$ (AGTPi), to the AGTP of the reference gas, usually $\mathrm{CO}_{2}$, and integrating it over time period $t$ :

$$
\operatorname{GTP}_{i}(t)=\operatorname{AGTP}_{i}(t) / A G T P_{\mathrm{CO}_{2}}(t)
$$

where the absolute global temperature change potential of pollutant $i$ in the time horizon $H\left(\operatorname{AGTP}_{i}(H)\right.$, $\left.\mathrm{K} \cdot \mathrm{kg}^{-1}\right)[4,30]$ is calculated as:

$$
\operatorname{AGTP}_{i}(H)=\int_{0}^{H} R F_{i}(t) R_{T}(H-t) d t
$$

where $R_{T}$ is the climate response $\left(\mathrm{K} \cdot \mathrm{m}^{2} \cdot \mathrm{W}^{-1} \cdot \mathrm{kg}^{-1}\right), H$ is the time horizon over which the absolute global temperature change potential is calculated (years). $R_{T}$ is given by the sum of exponentials:

$$
R_{T}(t)=\sum_{j=1}^{M}\left(c_{j} / d_{j}\right) \exp \left(-t / d_{j}\right)
$$

where $c_{j}$ is climate sensitivity $\left(\mathrm{K} \cdot\left(\mathrm{W} \cdot \mathrm{m}^{-2}\right)^{-1}\right)$, and $d_{j}$ is response time (years) (see Table 3 for numerical values). In this equation, the first term is the reaction of the mixed layer in the ocean to a forcing; the second term is the reaction of the deep layer in the ocean. Two exponential terms based on Boucher and Reddy for the non- $\mathrm{CO}_{2}$ greenhouse gases and $\mathrm{CO}_{2}$ are given in Equations (9) and (10), respectively.

$$
\begin{aligned}
\operatorname{AGTP}_{i}(H)=A_{i} \sum_{j=1}^{2} \tau c_{j} /\left(\tau-d_{j}\right)\left(\exp (-H / \tau)-\exp \left(-H / d_{j}\right)\right) & \\
\operatorname{AGTP}_{\mathrm{CO}_{2}}(H)= & A_{\mathrm{CO}_{2}} \sum_{j=1}^{2}\left[a_{0} c_{j}\left(1-\exp \left(-\frac{H}{d_{j}}\right)\right)\right. \\
& \left.+\sum_{i=1}^{3} \frac{a_{i} \tau_{i} c_{j}}{\tau_{i}-d_{j}}\left(\exp \left(-\frac{H}{\tau_{i}}\right)-\exp \left(-\frac{H}{d_{j}}\right)\right)\right]
\end{aligned}
$$

Table 3. Values of the climate sensitivity and response time coefficients [15].

\begin{tabular}{ccc}
\hline Coefficient & $\mathbf{1}^{\text {st }}$ Term & $\mathbf{2}^{\text {nd }}$ Term \\
\hline$c_{j}, \mathrm{~K}\left(\mathrm{~W} \cdot \mathrm{m}^{-2}\right)^{-1}$ & 0.631 & 0.429 \\
$d_{j}$, years & 8.4 & 409.5 \\
\hline
\end{tabular}


The concept of GTP was first introduced by Shine et al. [4] and further discussed in Shine et al. [31]. The change of normalized GTP values and absolute GTP values over 100 years in the case of pulse emissions of $\mathrm{CO}_{2}, \mathrm{~N}_{2} \mathrm{O}$, and $\mathrm{CH}_{4}$ are given in Figures 6 and 7, respectively.

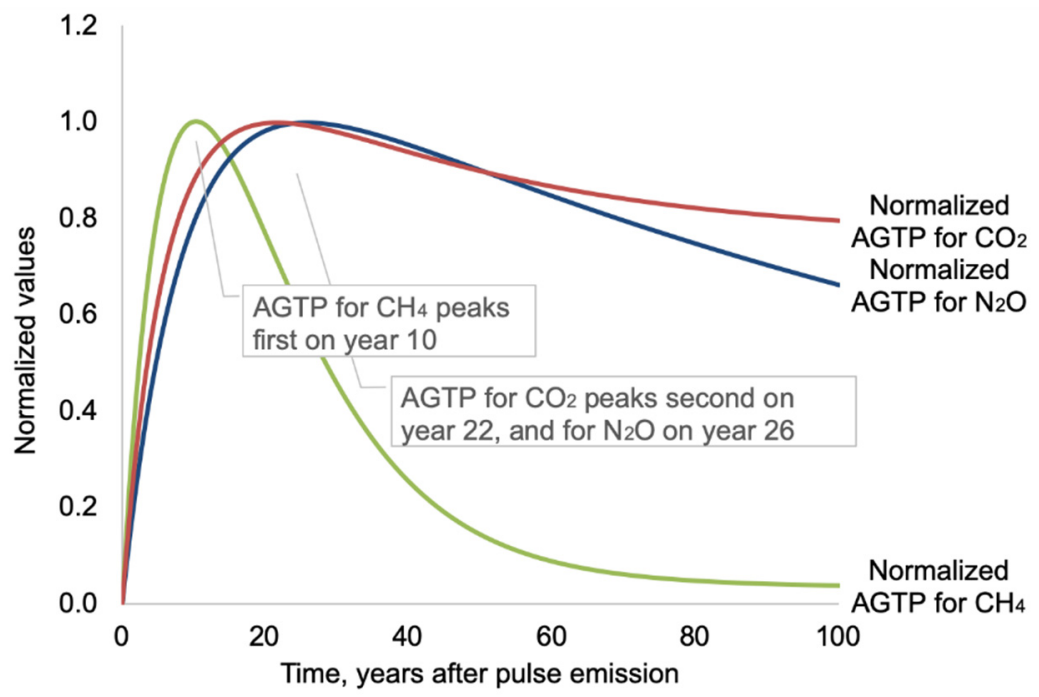

(a)

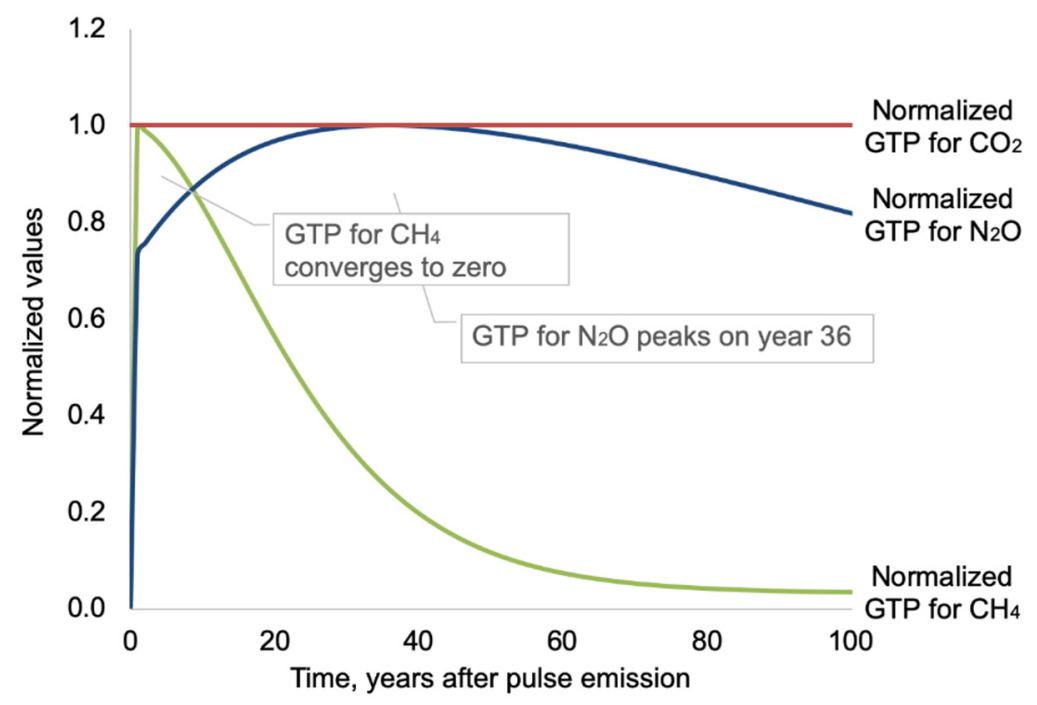

(b)

Figure 6. Normalized (a) absolute global temperature change potential (AGTP) (b) GTP values as a response to emission of $\mathrm{CO}_{2}, \mathrm{~N}_{2} \mathrm{O}$, and $\mathrm{CH}_{4}$ at year zero. The values are normalized to the maximum value of the corresponding AGTP or GTP of each gas, unitless. 


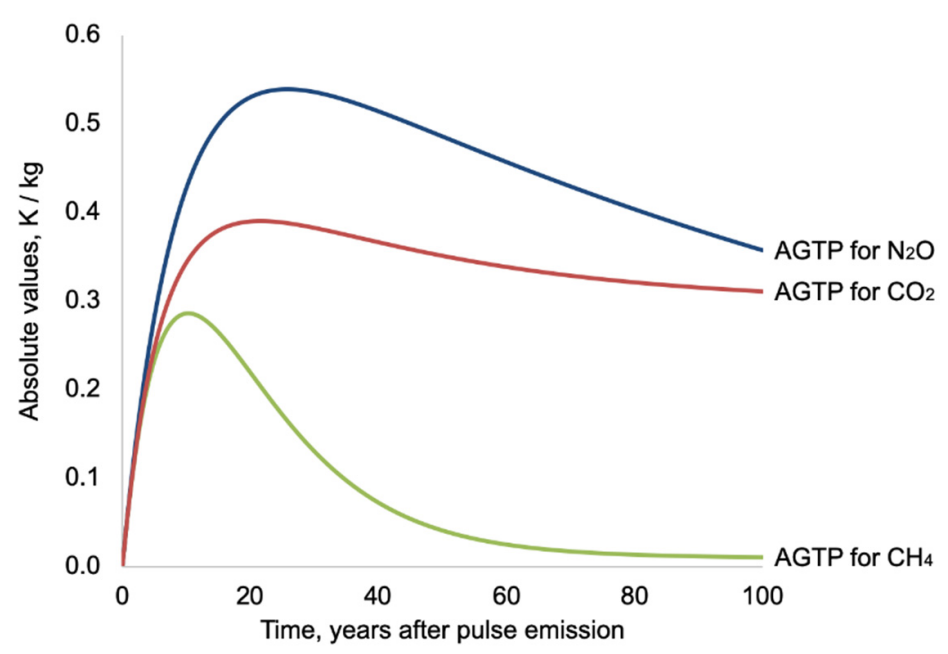

(a)

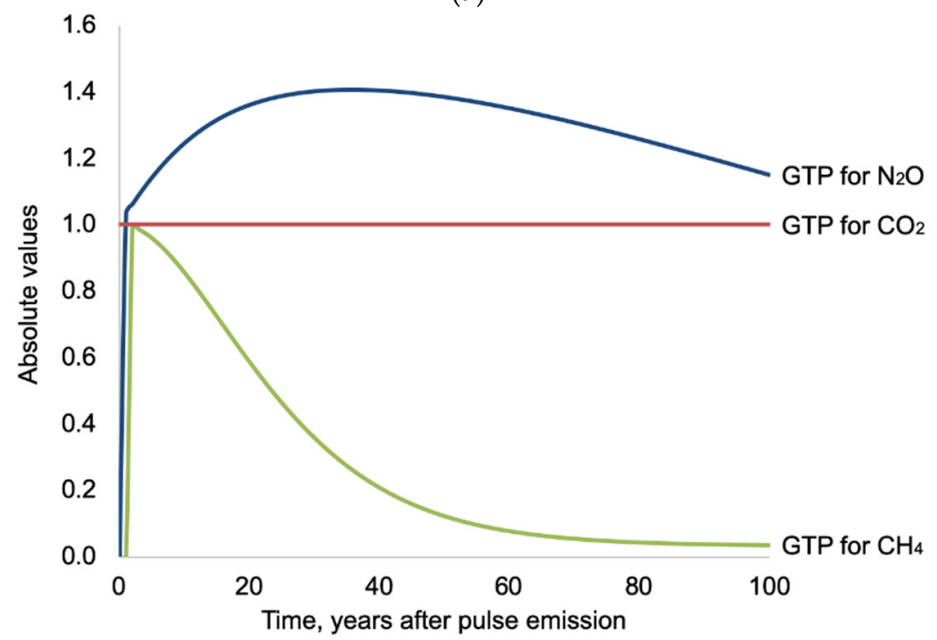

(b)

Figure 7. Absolute (a) AGTP and (b) GTP (unitless) values as a response to emission of $\mathrm{CO}_{2}, \mathrm{~N}_{2} \mathrm{O}$, and $\mathrm{CH}_{4}$ at year zero.

\subsection{Case Study-Agriculture Sector in Latvia}

In the agriculture sector, aggregated annual GHG emissions is a commonly used measure to characterize pressures and risks that GHGs produced on an ecosystem. The total rate of GHG emissions given as $\mathrm{t} \mathrm{CO}_{2}$ eq. from agriculture per country per year is estimated by following the IPCC guidelines for national GHG inventory [32]. The main contributors to GHG emissions from the agriculture sector are methane $\left(\mathrm{CH}_{4}\right)$ and nitrous oxide $\left(\mathrm{N}_{2} \mathrm{O}\right)$. Livestock enteric fermentation and addition of fertilizers to soils represent the largest emission sources, livestock manure management being a smaller source. In this study, the agricultural GHG emission results obtained and presented by Dace et al. [2] are used. In their study, Dace et al. [2] developed a system dynamics model of the Latvian agriculture sector and followed the IPCC guidelines for national GHG inventories [16] to calculate the sectoral GHG emissions.

The model included the following elements that usually create agricultural systems in the majority of countries: land management, production of livestock and crops, management of manure, fertilization of soil, also various decisions, such as choice of the practices of manure management and the type of crops produced. Thus, the interlinkages and complexity of the sector were simulated. The model was validated against the historic data and used for making GHG emission projections until 2030. In this study, we use the amount of GHG emissions estimated by Dace et al. [2] (see Figure 8) and apply the two methods provided in Section 2 to compare the obtained results expressed as aggregated GHG emissions in $\mathrm{CO}_{2}$ eq. 


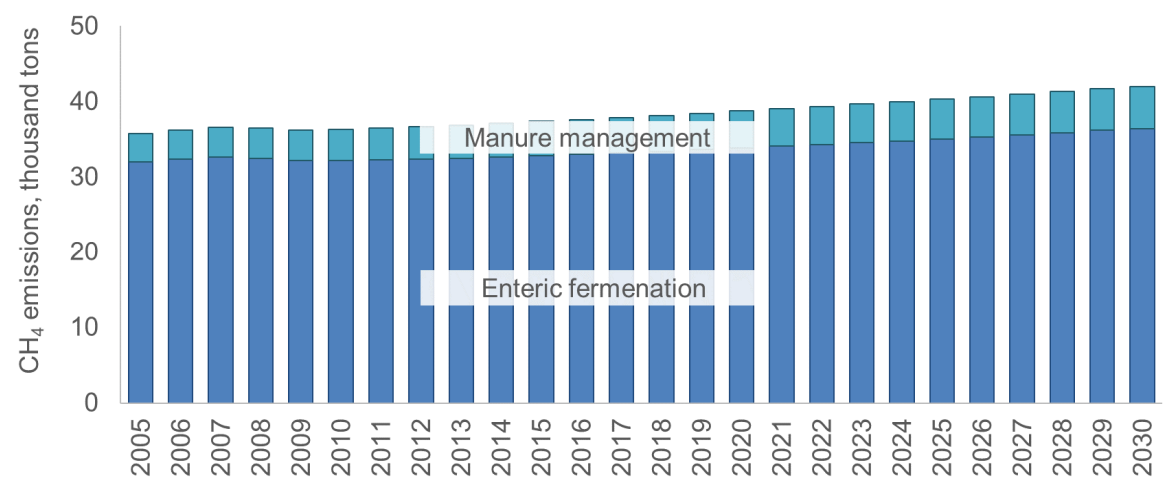

(a)

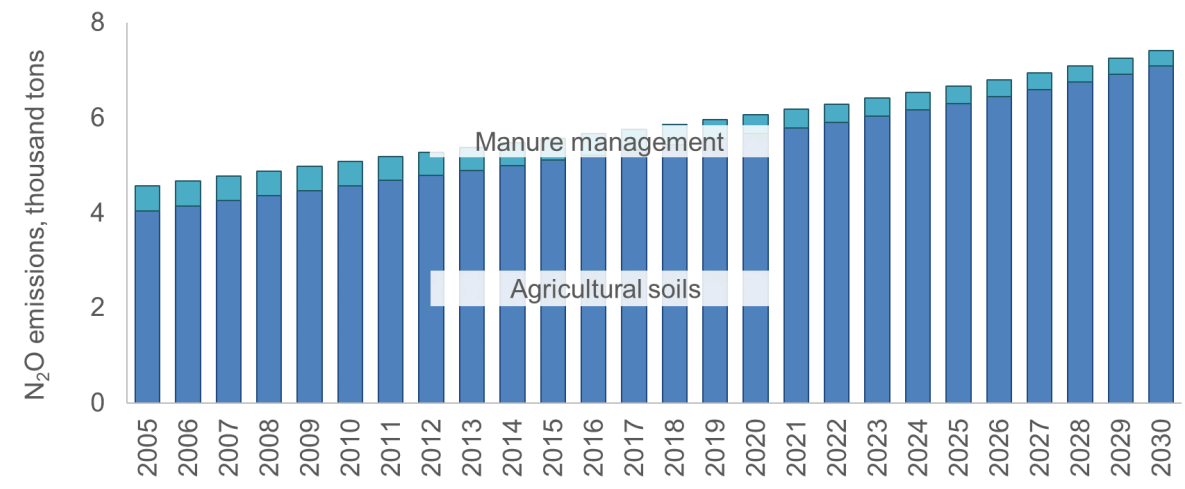

(b)

Figure 8. Annual (a) methane and (b) nitrous oxide emissions from the agriculture sector in Latvia, 2005-2030 (data from Dace et al. [2]).

\section{Results and Discussion}

The temporal effects of the annual emissions on the current year basis and the cumulative effect of this flow in the atmosphere for both continued emission flow and the eliminated emission flow are given in Figure 9.

In Figure 9, each curve represents the annual pulse emissions. Since the pollutants emitted in previous years are still in the atmosphere and decaying (see Figure 4 for individual emission decay trendlines), these pollutants are added up to emissions of the current year. The accumulation of these pulse emissions is continued until the pollutant has converged to zero concentration.

As can be seen in Figure 9, the flow rate of emission on the current year basis is relatively lower than the amount of the total cumulative emission in the air from the previous years. From this observation, two essential conclusions can be given. First, the importance to account and reduce also "small" amounts of emissions since these "small" amounts add up to a more significant cumulative effect. And second, the interference in the flow of the emissions will have a "visible" affect only a couple of decades later, since it takes time to decay emissions already accumulated in the atmosphere.

The cumulative GHG emissions calculated using the GWP100 values from the IPCC fourth [16] and fifth [15] assessment report and the emissions calculated using the decay function from BCCM show more substantial disparities in a shorter time horizon. At the same time, these disparities reduce in a longer time horizon (see Figure 10).

The use of the latest GWP100 values from IPCC 2013, which include carbon cycle feedback [15], results in emission curves located closer to the curves obtained with BCCM than the use of GWP100 values taken from IPCC 2006 [16]. Especially significant convergence towards numbers obtained by BCCM is evident for $\mathrm{CH}_{4}$ emissions using IPCC 2013 values instead of IPCC 2006 values. As one of the thought-provoking differences between results in IPCC and BCCM methods, the different nature of the line shapes should be stressed out. Since $\mathrm{CH}_{4}$ decay has an evident non-linear nature, the most 
significant difference in the results is created in the near-term estimates of the $\mathrm{CH}_{4}$ impacts. Similar findings are given in the work by Allen et al. [5], where the most significant misrepresentation of the impacts using GWP is evident in the case of methane and aerosol emissions. In Figure 10, this difference is given between the straight lines of IPCC 2006 and IPCC 2018 results and the non-linear line of BCCM results. Where an almost twofold difference is created in the short-term analysis, this difference cannot also be compensated with overestimated $\mathrm{N}_{2} \mathrm{O}$ impacts, because $\mathrm{N}_{2} \mathrm{O}$ results by BCCM follow a linear nature until 2030 relatively tightly.

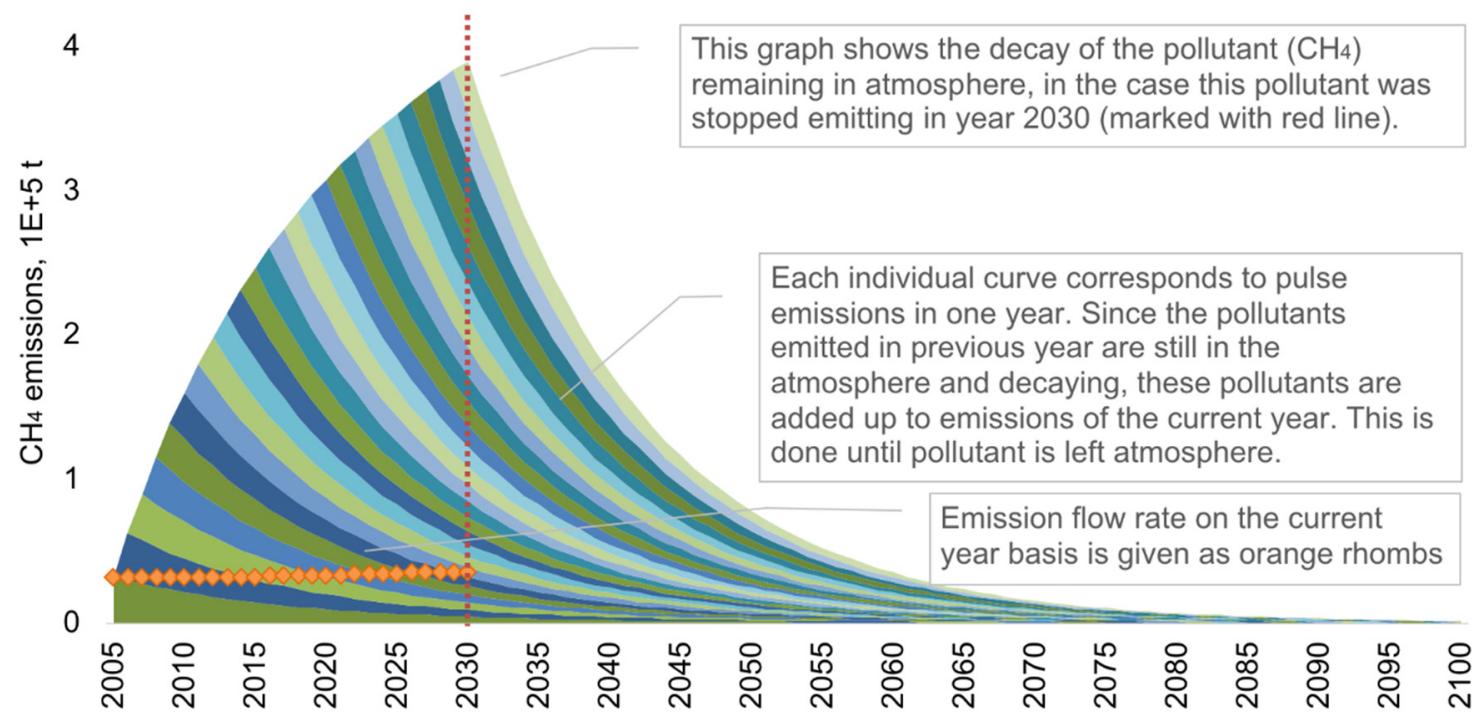

Figure 9. The emission flow rate on the current year basis and the cumulative effect of this flow in the atmosphere for continued emission flow and the elimination of the emission flow: an example of $\mathrm{CH}_{4}$ emissions from enteric fermentation in Latvia, 2005-2100.

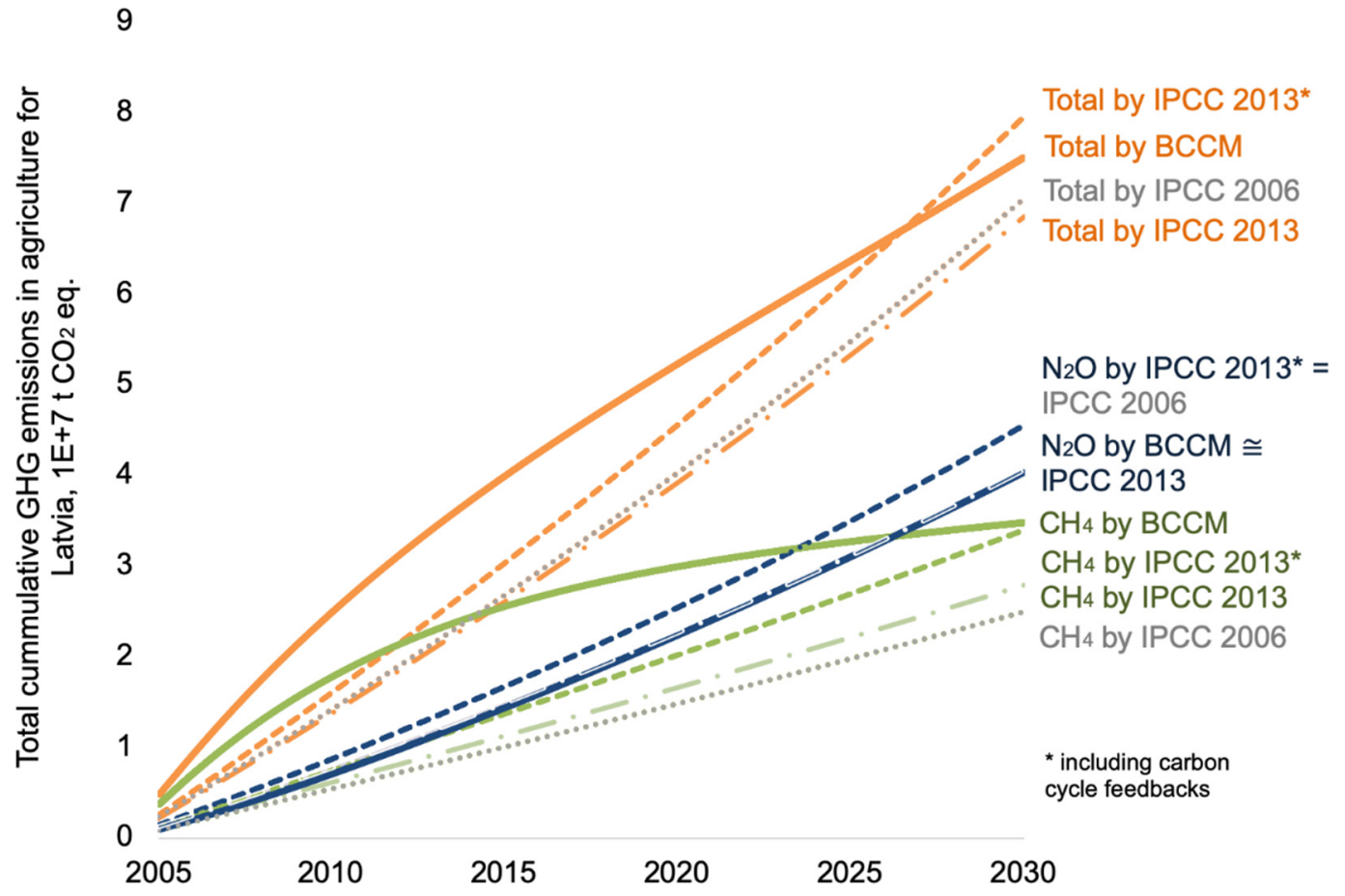

Figure 10. The comparison of the cumulative GHG emissions calculated using the GWP values from IPCC 2006 and IPCC 2013 and the decay function using the Bern Carbon Cycle Model (BCCM). 
These differences in the total cumulative amounts of GHG emissions are due to the use of constant GWP values in the IPCC methodology, while in decay function, the GWP value changes with time; see Figure 11 for GWP values for $\mathrm{N}_{2} \mathrm{O}$ emissions and Figure 12 for $\mathrm{CH}_{4}$ emissions.

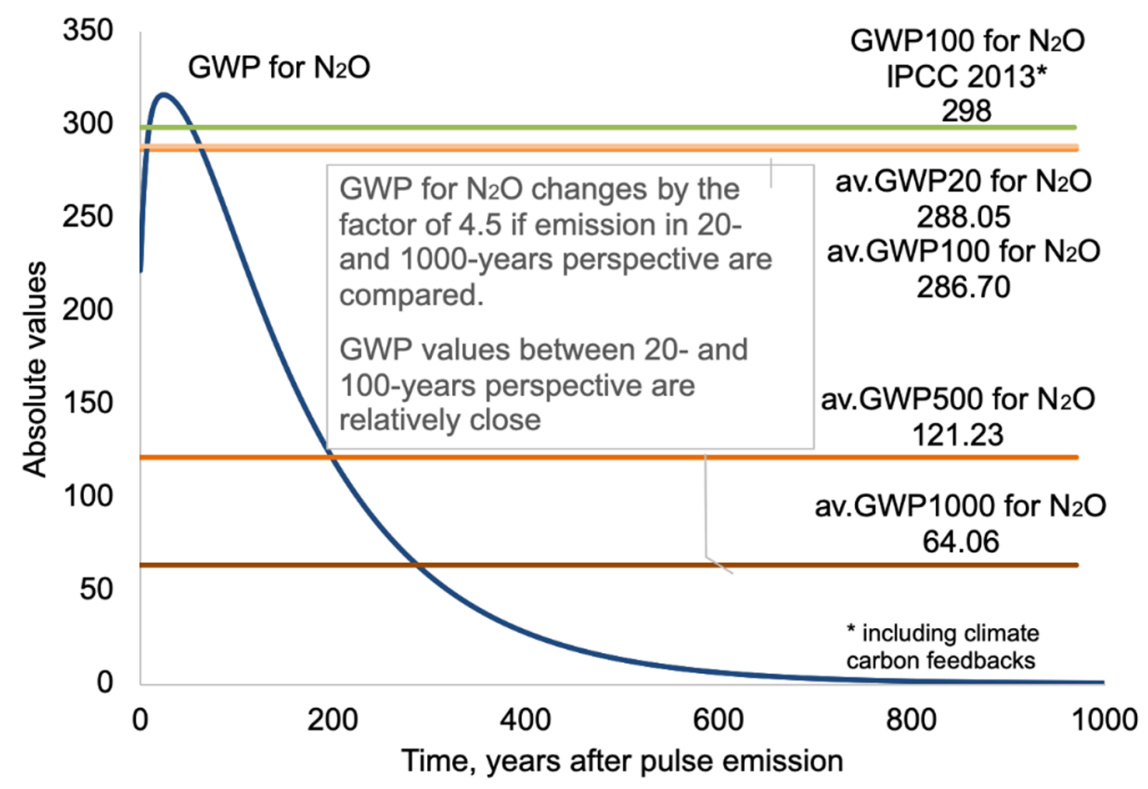

Figure 11. Absolute GWP values for $\mathrm{N}_{2} \mathrm{O}$ emissions given using the $\mathrm{BCCM}$ "GWP for $\mathrm{N}_{2} \mathrm{O}^{\text {" }}$ and average GWP values for the first 20 years after pulse emission of $\mathrm{N}_{2} \mathrm{O}$ named "av.GWP20 for $\mathrm{N}_{2} \mathrm{O}^{\text {" }}$ and has the value of 288.05; for the first 100 years- "av.GWP100 for $\mathrm{N}_{2} \mathrm{O}^{\text {"; }}$; for the first 500 and 1000 years- "av.GWP500 for $\mathrm{N}_{2} \mathrm{O}$ " and "av.GWP1000 for $\mathrm{N}_{2} \mathrm{O}$ ". GWP value for the first 100 years given in the IPCC 2013, including the carbon cycle feedback, has the value of 298 and is given as "GWP100 for $\mathrm{N}_{2} \mathrm{O}$ IPCC $2013^{* \prime \prime}$, unitless.

The high sensitivity of the GWP values for the chosen time frame for $\mathrm{CH}_{4}$ and $\mathrm{N}_{2} \mathrm{O}$ is due to the non-linear nature and different mathematical functions used for approximation of these decay functions. The difference in the average values of GWP for different time horizons can be substantial, and the obtained conclusions can be misleading. When using these averages, a situation is also possible when a longer time horizon diminishes the importance of local and relatively short lifetime emissions, such as $\mathrm{CH}_{4}$. For example, the described situation is evident that in the case of $\mathrm{N}_{2} \mathrm{O}$ emissions, the time frame of 20 or 100 years does not change the applied GWP values so significantly as they change in the case when $\mathrm{CH}_{4}$ is assessed either in 20 or 100 years (see Figure 12).

Also, the perturbation time of $\mathrm{CH}_{4}$ emissions is approximately ten times less than the perturbation time of $\mathrm{N}_{2} \mathrm{O}$ emissions. Thus, the use of single metrics for such different behaviour is rather challenging. The difference in the emissions' trendlines, given in Figure 10, between the GWP values from IPCC and the values from BCCM is visually explained in Figures 11 and 12, where GWP100 values used in IPCC2013 for $\mathrm{N}_{2} \mathrm{O}$ and $\mathrm{CH}_{4}$ emissions graphically are located between different segments. In Figure 11, for $\mathrm{N}_{2} \mathrm{O}$ emissions, the value of GWP100 from IPCC2013 is 298, including carbon cycle feedbacks. This value of 298 is higher than the mathematical average of GWP20 and GWP100 values for $\mathrm{N}_{2} \mathrm{O}$. While for $\mathrm{CH}_{4}$ emissions given in Figure 12, the value of GWP100 from IPCC2013 is 34, including carbon cycle feedbacks. This value of 34 is in between the mathematical average of GWP20 and GWP100 values for $\mathrm{CH}_{4}$. Thus, these selected GWP100 values from IPCC describe different segments of the emission decay period for $\mathrm{N}_{2} \mathrm{O}$ and $\mathrm{CH}_{4}$ and, therefore, create differences in the obtained results.

Also, longer time horizons, in general, give lower GWP values. Thus, it is always better to select a longer time horizon to have a smaller impact, but does it provide a reasonable picture of these impacts? It can be further discussed, how can the assessment of the impact at the government or enterprise-level 
reasonably give an interpretation for the values of the possible impacts in 100 or 500 years? And how realistic is it that the cost of these created impacts in 100 or even in the next 20 years will be adequately attributed to the producer or consumer of today? In Figure 10, the total cumulative GHG emissions calculated using GWP values suggested by the IPCC and decay functions are compared until 2030. Usually, the comparison is used to show the created impact. In fact, the effect of the emissions occurring in the last year (2030) and a couple of years before 2030 are not included in the calculations when using the decay function. For the more realistic impacts, see Figure 13a.

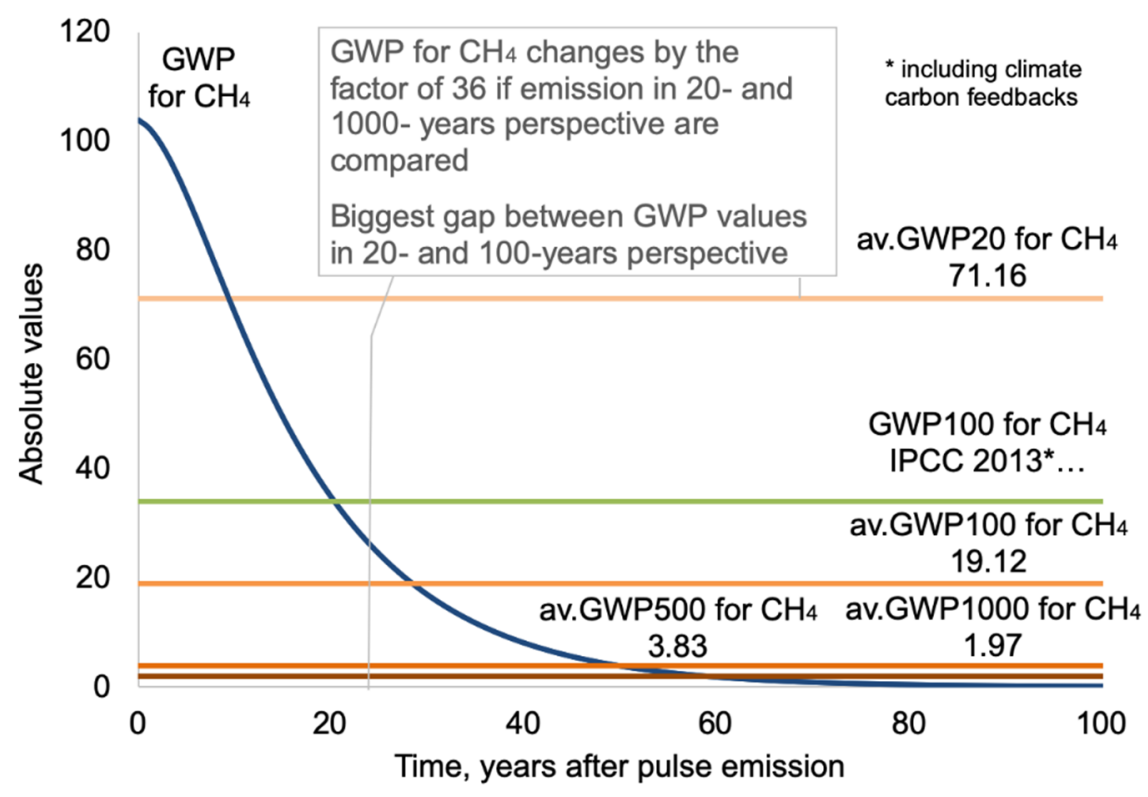

Figure 12. Absolute GWP values for $\mathrm{CH}_{4}$ emissions given using the BCCM named "GWP for $\mathrm{CH}_{4}$ " and average GWP values for the first 20 years after pulse emission of $\mathrm{CH}_{4}$ named "av.GWP20 for $\mathrm{CH}_{4}$ " and has the value of 71.16, for the first 100 years-"av.GWP100 for $\mathrm{CH}_{4}$ "; for first 500 and 1000 years-“av.GWP500 for $\mathrm{CH}_{4}$ " and "av.GWP1000 for $\mathrm{CH}_{4}$ ". GWP value for the first 100 years given in the IPCC 2013, including carbon cycle feedback, has the value of 34 and is given as "GWP100 for $\mathrm{CH}_{4}$ IPCC 2013*", unitless.

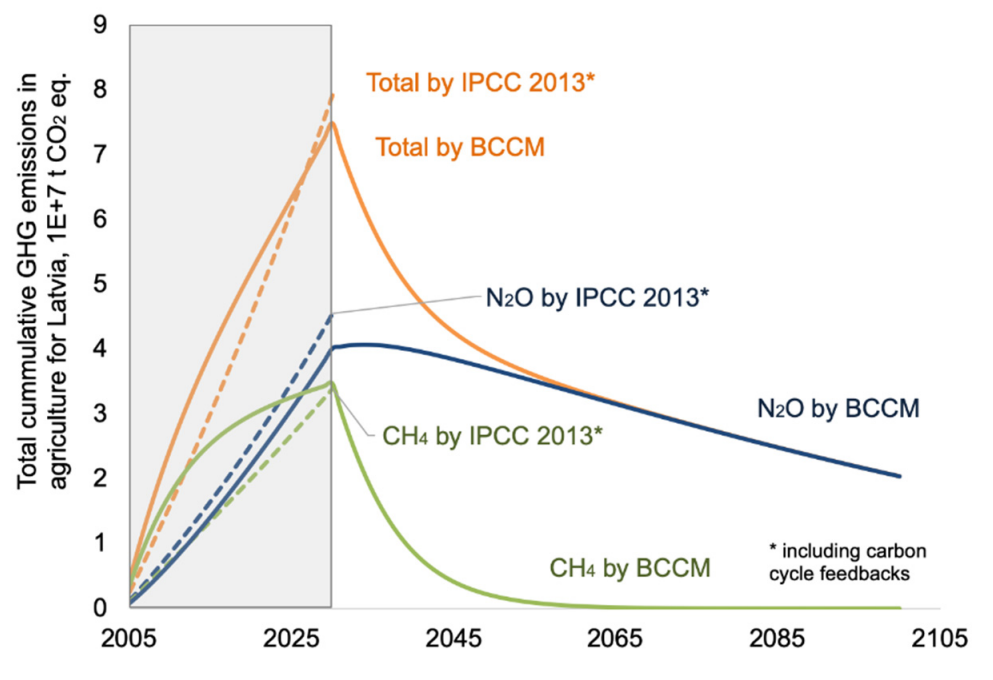

(a)

Figure 13. Cont. 


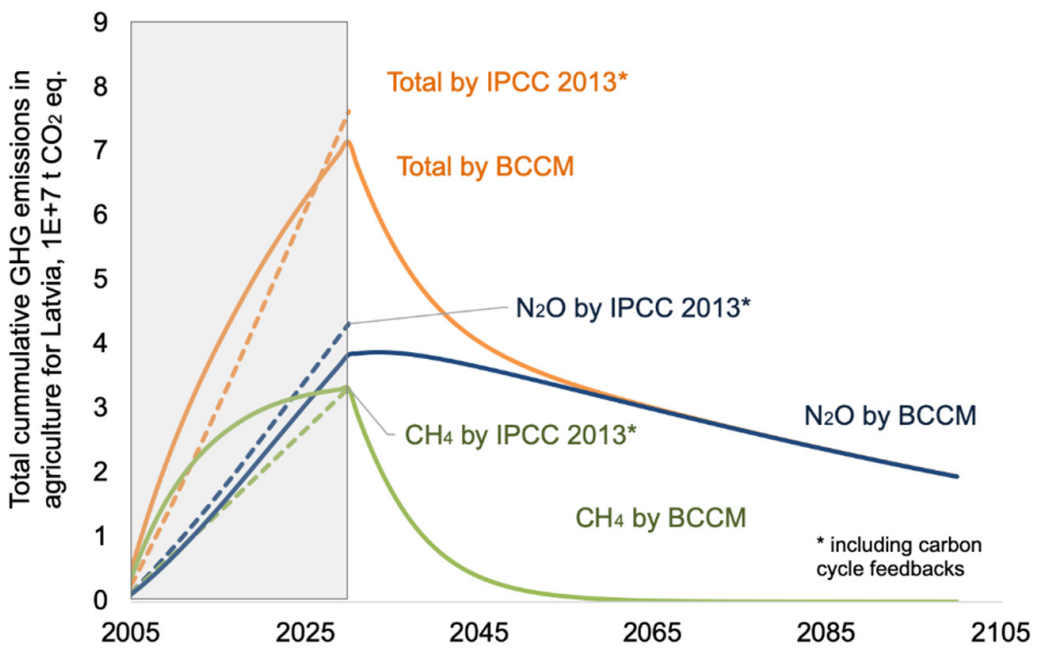

(b)

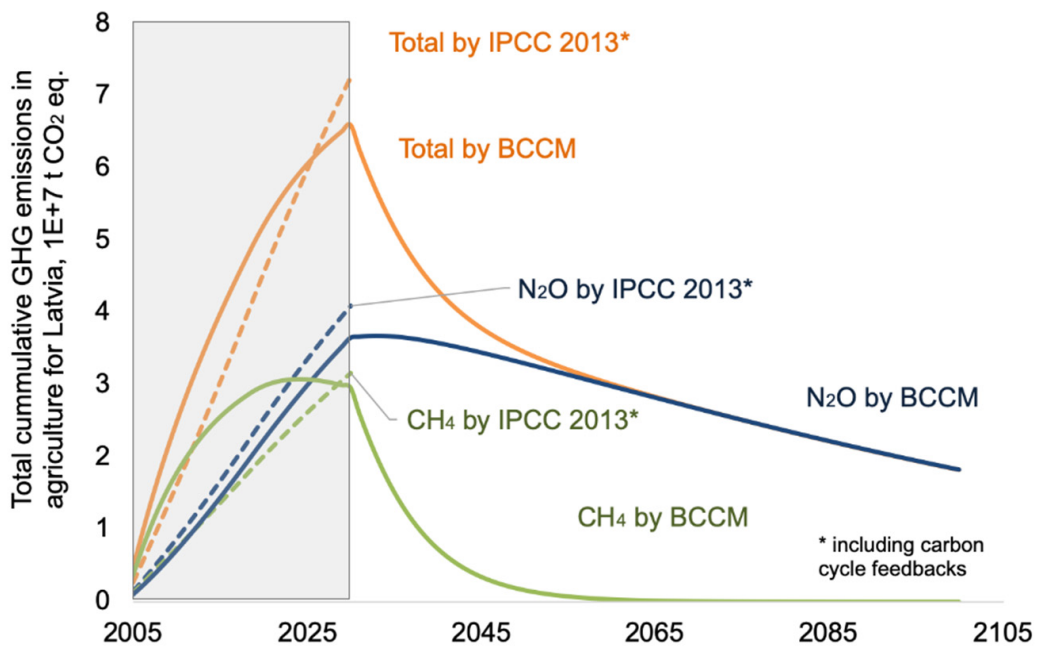

(c)

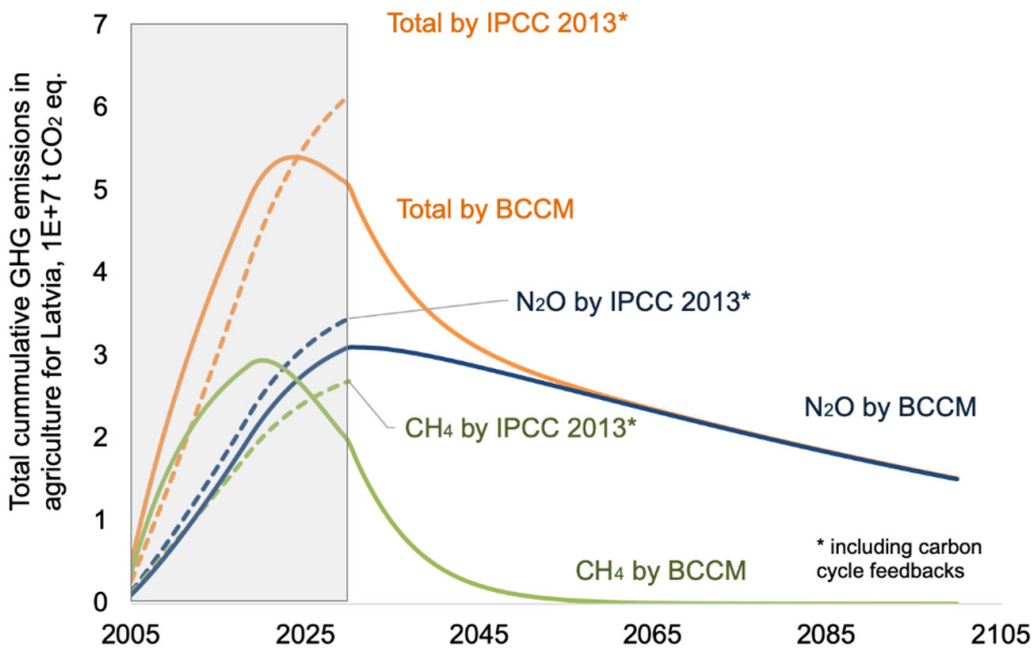

(d)

Figure 13. The comparison of the total cumulative GHG emissions calculated using IPCC methodology and decay function before and after year 2030, Latvia (a) reference case or business as usual based on Dace et al. [2] (b) constant emission after 2020, (c) declining emissions by $2 \%$ after 2020, (d) declining emissions by $10 \%$ after 2020 . 
Assuming that after the year 2030, no more emissions are occurring, Figure 13a shows how the amounts of the emissions released to the atmosphere until 2030 slowly decay. The figure shows that

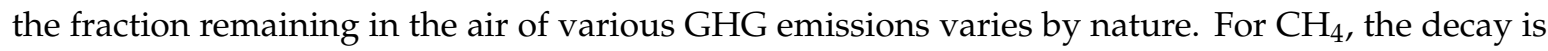
much faster, while $\mathrm{N}_{2} \mathrm{O}$ has not even halved since its release. Similar findings of the lack of appropriate comparison between short-lived GHGs (in this case, $\mathrm{CH}_{4}$ ) and long-lived GHGs $\left(\mathrm{N}_{2} \mathrm{O}\right)$ are discussed in work by Boucher et al. [30]. The authors explain that difficulty in using GWP for short-lived GHGs is because the GWP value does not consider that the radiative forcing of these short-lived GHGs has time to relax and reach equilibrium in the analyzed time horizon. Thus, Boucher et al. [30] have introduced the GTP concept that generalizes climate impacts and considers different climate responses for both short and long-lived GHG emissions.

The faster decay of $\mathrm{CH}_{4}$ is usually used as the argument to reduce the importance of this emission, especially in the agriculture sector, where $\mathrm{CH}_{4}$ emissions have a significant share in the total impact categories; see Figure 14a,b.

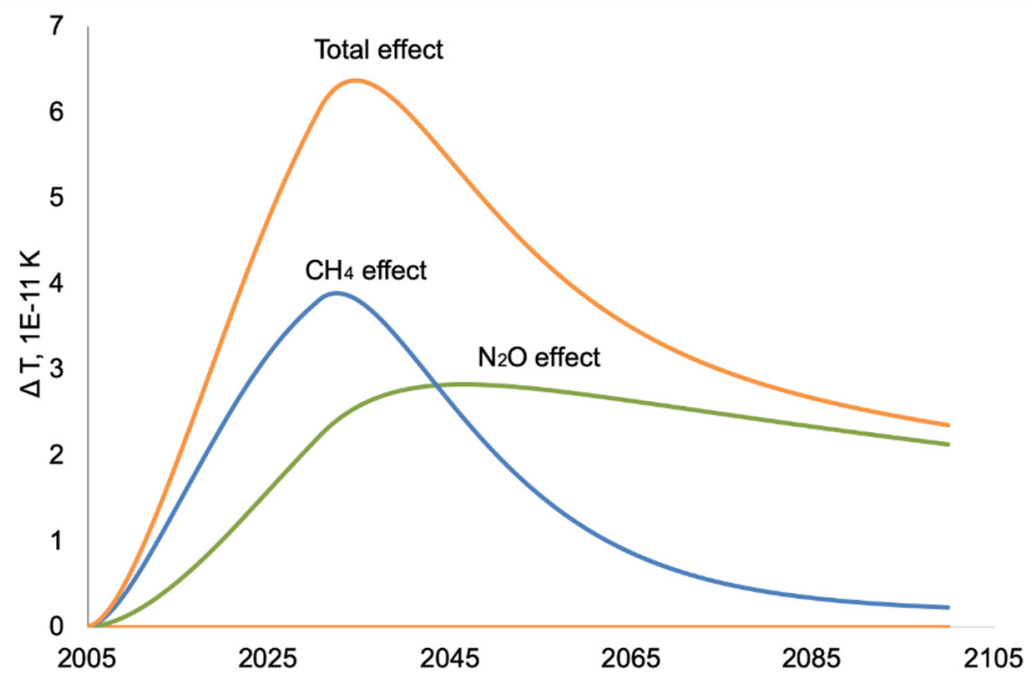

(a)

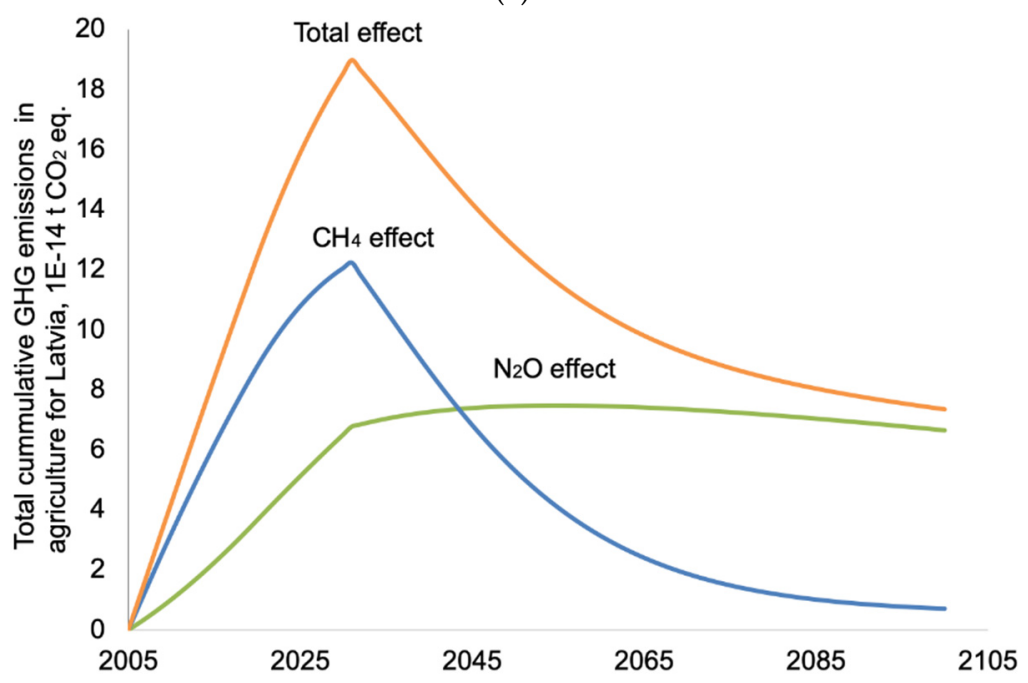

(b)

Figure 14. (a) Absolute global temperature change potential (AGTP) and (b) global temperature change potential (GTP) calculated for the emissions from agriculture in Latvia. 
If the impact on the GTP from $\mathrm{CH}_{4}$ is assessed, it can be seen that $\mathrm{CH}_{4}$ shows a more obvious temperature change effect in a shorter run and, in total, contributes to more than half of the temperature change effect created by the agriculture in Latvia, as given in Figure 14.

In this case, various different scenarios of the agriculture emission are modelled, such as constant emissions or decreasing emissions; see Figure 15. As can be seen, Figure 13a-c depict related trends very precisely. For example, the total emissions from agriculture in Latvia in the year 2030 between scenarios given in Figure 15a, business as usual or $2 \%$ growth of emissions and Figure 15b, constant emissions after the year 2020 calculated based on BCCM will differ by $4 \%$ only. This example shows how hard it is to reach the emission reductions due to accumulation and long perturbation time of these emissions in the atmosphere. In work by Olivié and Peters [27], the common characteristics and differences between GWP and GTP are discussed. Both methods are designed to be simple tools for comparing impacts to climate from several types of GHG emissions. Both methods refer to the pulse emission of some specific GHG in comparison to the pulse emission of the same quantity of reference $\mathrm{CO}_{2}$ emissions, while the difference is in the used mathematical model-where GWP is based on comparing the changes in radiative forcing overtime, and GTP on global mean temperature changes over time [4].

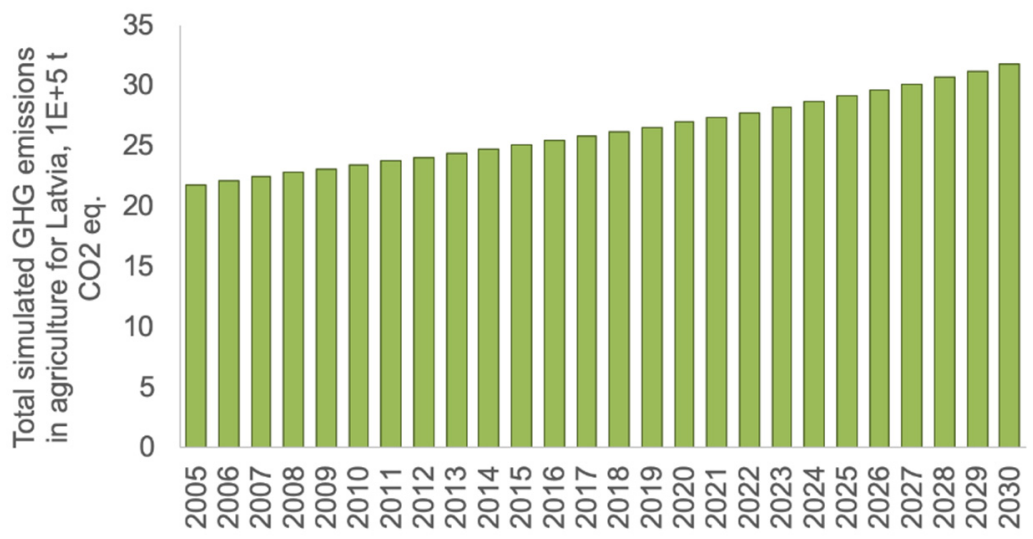

(a)

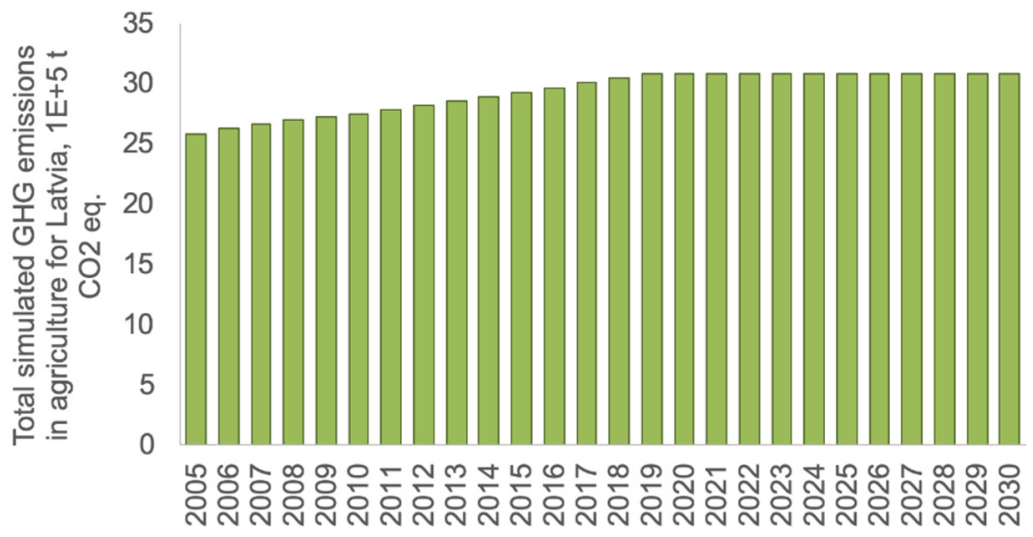

(b)

Figure 15. Cont. 


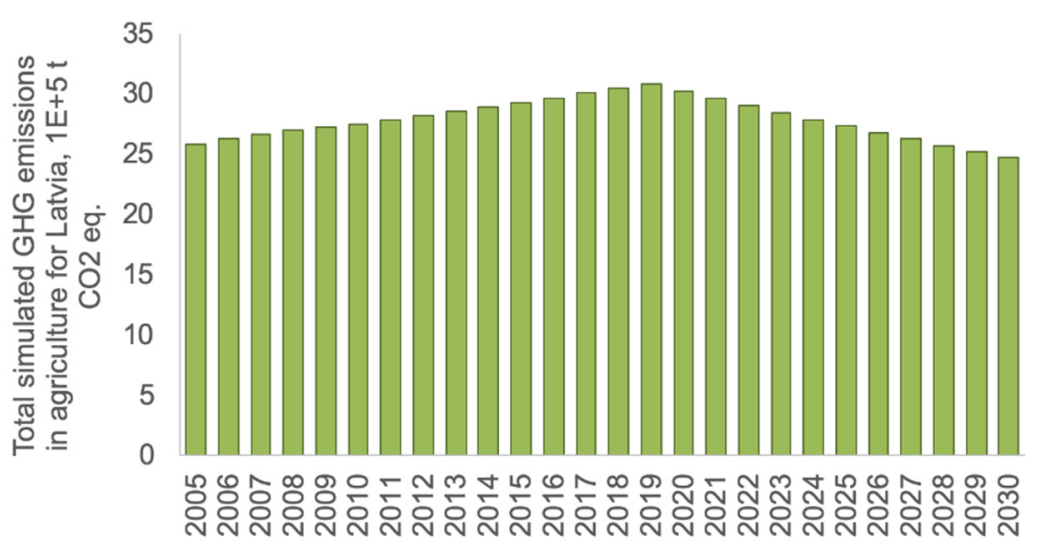

(c)

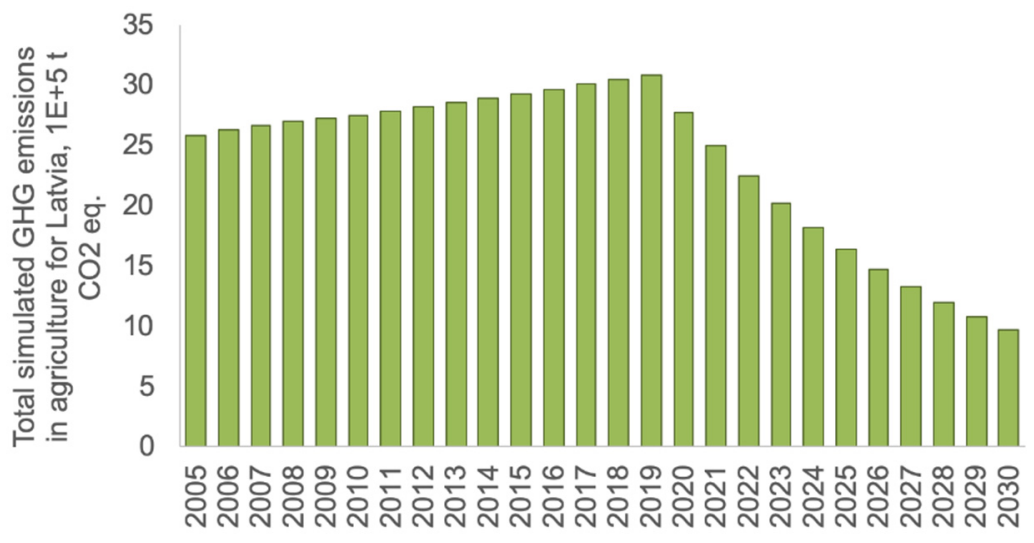

(d)

Figure 15. Modelled scenarios for the emissions from agriculture in Latvia, (a) reference case or business as usual based on Dace et al. [2], (b) constant emission after 2020, (c) declining emissions by $2 \%$ after 2020, and (d) declining emissions by $10 \%$ after 2020 .

The most significant difference between GWP and GTP is that GTP is an end-point metrics, while GWP is a cumulative measure of climate change. Thus, the value of radiative forcing is of great importance in the analysis of GTP, and more weight is given to climate effects of radiative forcing that come later in the perturbation time of the analyzed pollutants. Thus, for the emissions with a shorter perturbation time, there will be a more significant difference between the results of GWP and GTP results. This theory implies that the GWP assessment gives an overestimation of the short-lived pollutants for the mitigation of climate change. In work by Boucher and Reddy [30], the difference between black carbon emissions for 100 years perspective in the case of using GTP gave seven times smaller impact than the corresponding GWP assessment. These findings are also in agreement with the work of Shine et al. [4]. Also, the choice of the time horizon to evaluate the impacts of the emissions is of significant importance. By far, the most common practice is to use a 100-year time horizon, since it is used in the Kyoto Protocol [27], but there is no scientific justification in using this particular time horizon. The larger the time horizon is chosen, the fewer effects can be attributed to short-lived pollutants [30]. On the other hand, sustainability cannot be achieved if only long-lived pollutants are accounted and restricted, while short-lived continue to degrade local ecosystems. Therefore, here, both short-term and long-term impacts on sustainability should be assessed and balanced.

Moreover, the choice of the time horizon of 20 years or 100 years or some other time horizon is still not scientifically justified by any concrete evidence [30]. Thus, the obtained results are also sensitive to the assumed time horizon and can lead to contradicting conclusions. 
Our findings are also in agreement with work published by Shimako [7] and Shimako et al. [8]. The authors of the research studied the same total amount of emissions but taken with two different emission timing profiles. One emission profile was constant through the simulation, another emission profile peaked in the beginning and then was zero for $4 / 5$ of the simulation. Due to this difference in the emission profiles, the temporal effects of these two emission profiles also differ. In contrast, the total amount of emissions at the end of the simulation was the same for both profiles. In case GWP would be multiplied by the total amount of emissions, the obtained results would be the same for both profiles. This phenomenon is also evident in our findings-the cumulative emissions have different impact profiles when the same amount of total emissions is considered using temporal impacts.

Since the short-lived GHG emissions affect local environments in more apparent patterns, such as effects on air quality, human health, and local ecosystems, in work by Rypdal et al. [33], it was proposed to regulate short-lived emission in regional policy contexts. The influence of the emissions on local metrics is reviewed in detail in work by Rypdal et al. [34] and by Levasseur et al. [6].

Work by Olivié and Peters [27] also explains that in coupled systems, the temperature changes will also affect the ocean in two ways. Firstly, the absorption of $\mathrm{CO}_{2}$ directly by the ocean will increase if the temperature will rise. Secondly, ocean circulation patterns will be changing, due to direct effects from increased respiration and photosynthesis or indirectly by changes in precipitation. Also, the authors discuss how various changes in these coupled systems might influence the numerical values used in IRF. Nevertheless, we would like to stress that, in this work, the precise numerical values were not of such high importance as the depiction of overall dynamics and different results that can be obtained using two different methodological approaches.

Also, work by Jardine et al. [35] shows that various feedbacks exist when $\mathrm{CH}_{4}$ emissions are analyzed. For example, the global atmospheric lifetime of $\mathrm{CH}_{4}$ is defined by the amount of atmospheric concentration of $\mathrm{CH}_{4}\left(\mathrm{CH}_{4}\right.$ burden) divided by the amount of annual removal of $\mathrm{CH}_{4}$ from the atmosphere $\left(\mathrm{CH}_{4}\right.$ sink). Thus, increasing the concentration of $\mathrm{CH}_{4}$ in the atmosphere will lead to longer global atmospheric lifetimes. In work by Holmes [36], the strength of chemical feedback for $\mathrm{CH}_{4}$ was analyzed using meteorological, chemical, and emissions factors. The research shows that this feedback depends weakly (likely in the $10 \%$ range) on temperature, insolation, water vapour, and emissions of $\mathrm{NO}$. While perturbation time of $\mathrm{CH}_{4}$ might rise as high as $40 \%$ and more, this means that close accounting of the balance in $\mathrm{CH}_{4}$ is needed in order to have valid assumptions about the time when "constant" values cannot be treated as constants anymore.

To sum up, we believe that both types of emission accounting (the constant GWP values for a 100-year time horizon (GWP100) and the time dynamic GWP values for a 100-year time horizon obtained by using the BCCM) are valuable to use; each has its strength and weaknesses. Thus, we propose to also look on the temporal impacts of emissions, since it might help in designing more precisely targeted policy measures appropriate for the chosen mitigation priorities.

As given in the report by Jardine et al. [35], $\mathrm{CH}_{4}$ emissions decay about ten times faster than $\mathrm{N}_{2} \mathrm{O}$, but from the other point of view, policy measures targeting $\mathrm{CH}_{4}$ reduction will also show the effect on the reduction of climate change ten times faster than measures targeting $\mathrm{N}_{2} \mathrm{O}$. Also, the report by the United Nations Environment Programme and the World Meteorological Organization [37] shows that the adoption of policies targeting short-lived GHGs would allow reaching climate change mitigation targets with higher confidence. The report also shows that $\mathrm{CO}_{2}$ reduction measures alone would exceed the set temperature thresholds anyway already in the near term. In contrast, only $\mathrm{CH}_{4}$ reduction measures would keep the temperature below the threshold in the near term while exceeding the limit later because of the effect of other GHGs. As the opposing argument for stricter control of long-term pollutants is the fact that any technological solution and policy measure will be implemented only for the finite time. Usually, the selected time horizon is much shorter than the consequences of the pollution associated with these technologies. 


\section{Conclusions}

In this paper, two methods for GHG emission accounting were compared. First, using the constant GWP values for a 100-year time horizon (GWP100) and second, the time dynamic GWP values for a 100-year time horizon obtained by using the BCCM that takes into consideration the climate system response to the amount, time and decay rate of the emitted pollutant. The GWP100 values are the default emission metric suggested by the IPCC for the annual emission accounting, and it is considered a relatively simple and easy to use the method. Although no scientific evidence backs the use of GWP100 and, more importantly, GWP100 has "no direct estimation of any climate system responses or direct link to policy goals" (Myhre et al. [15]; Cherubini et al. [38]), policymakers widely use the GWP100 values in designing GHG emission mitigation strategies and international agreements, like the Kyoto protocol and Paris agreement.

The results of our study show that the cumulative emissions have different impact profiles when the same amount of total emissions is considered using temporal impacts. The obtained results are also sensitive to the assumed time horizon and can lead to contradicting conclusions. The high sensitivity of the GWP values for the chosen time frame for $\mathrm{CH}_{4}$ and $\mathrm{N}_{2} \mathrm{O}$ is due to the non-linear nature and different mathematical functions used for approximation of these decay functions. The difference in the average values of GWP for different time horizons can be substantial, and obtained conclusions can be misleading. When using these averages, a situation is also possible when a longer time horizon diminishes the importance of local and relatively short lifetime emissions, such as $\mathrm{CH}_{4}$. For example, the described situation is evident that in the case of $\mathrm{N}_{2} \mathrm{O}$ emissions, the time frame of 20 or 100 years does not change the applied GWP values so significantly as they change in the case when $\mathrm{CH}_{4}$ is assessed either in 20 or 100 years.

If the impact on the GTP from $\mathrm{CH}_{4}$ is assessed, it can be seen that $\mathrm{CH}_{4}$ shows a more obvious temperature change effect in a shorter run and, in total, contributes to more than half of the temperature change effect created by the agriculture in Latvia.

The BCCM facilitates the selection of the time horizon needed for the specific purpose and expresses the results of policy decisions as to the effect of emissions on the global temperature change potential. The use of GWP100 is still useful and needed as (at least) two purposes of the emission accounting should be separated-one is for the emission inventory, the other is for the policy planning. The inventory is needed to keep track of the annual emission rates and assess the trends and success achieved in the emissions mitigation in the past, and GWP100 is useful for the purpose.

Meanwhile, policy strategies and instruments aim to achieve some desirable behaviour that may effectively govern a system in the future. And the GWP values obtained by using the BCCM would be much more useful for the purpose. Although "countries and the international community have made significant investments in inventory systems" [16] reconsideration and use of other methodology by the policymakers might eventually be less costly than dealing with consequences of climate change and wrong decisions (sub-optimal policies). Application of the BCCM would facilitate finding more efficient mitigation options for various pollutants, analyze multiple parts of the climate response system at a specific time in the future (amount of particular pollutants, temperature change potential), or analyze different solutions for reaching the emission mitigation targets at regional, national, or global levels.

Author Contributions: Conceptualization, L.T., E.D., M.T.K.; methodology, L.T.; Software, E.D.; validation, L.T., E.D.; formal analysis, L.T., E.D., M.T.K.; investigation, L.T.; resources, L.T., E.D.; data curation, L.T.; writing-original draft preparation, L.T.; writing—review and editing, L.T., E.D., M.T.K.; visualization, L.T.; supervision, M.T.K.; project administration, L.T., M.T.K.; funding acquisition, L.T. All authors have read and agreed to the published version of the manuscript.

Funding: This research was funded by European Union's Horizon 2020 research and innovation programme under the Marie Sklodowska-Curie grant agreement No 798365.

Acknowledgments: This publication is the selected article from the European Biomass Conference and Exhibition (EUBCE) 2019 conference. And the methodology used in the article was initially presented in the EUBCE 2019 conference for the case study on biorefineries under the title Timma L. and Parajuli R. 2019, Time Dynamics in Life Cycle Assessment-Exemplified by a Case Study on Biorefineries. In European Biomass Conference 
and Exhibition Proceedings., ETA-Florence Renewable Energies, s. 1599-1603, Lisbon, Portugal, 27/05/2019. https://doi.org/10.5071/27thEUBCE2019-4DO.5.2.

Conflicts of Interest: The authors declare no conflict of interest.

\section{References}

1. Mussatto, S.I. Challenges in Building a Sustainable Biobased Economy. Ind. Crops Prod. 2017, 106, 1-2. [CrossRef]

2. Dace, E.; Muizniece, I.; Blumberga, A.; Kaczala, F. Searching for solutions to mitigate greenhouse gas emissions by agricultural policy decisions-Application of system dynamics modeling for the case of Latvia. Sci. Total Environ. 2015, 527-528, 80-90. [CrossRef] [PubMed]

3. Cherubini, F.; Fuglestvedt, J.; Gasser, T.; Reisinger, A.; Cavalett, O.; Huijbregts, M.A.J.; Johansson, D.J.A.; Jørgensen, S.V.; Raugei, M.; Schivley, G.; et al. Bridging the gap between impact assessment methods and climate science. Environ. Sci. Policy 2016, 64, 129-140. [CrossRef]

4. Shine, K.P.; Fuglestvedt, J.S.; Hailemariam, K.; Stuber, N. Alternatives to the Global Warming Potential for comparing climate impacts of emissions of greenhouse gases. Clim. Chang. 2005, 68, 281-302. [CrossRef]

5. Allen, M.R.; Shine, K.P.; Fuglestvedt, J.S.; Millar, R.J.; Cain, M.; Frame, D.J.; Macey, A.H. A solution to the misrepresentations of $\mathrm{CO} 2$-equivalent emissions of short-lived climate pollutants under ambitious mitigation. NPJ Clim. Atmos. Sci. 2018, 1,1-8. [CrossRef]

6. Levasseur, A.; Cavalett, O.; Fuglestvedt, J.S.; Gasser, T.; Johansson, D.J.A.; Jørgensen, S.V.; Raugei, M.; Reisinger, A.; Schivley, G.; Strømman, A.; et al. Enhancing life cycle impact assessment from climate science: Review of recent findings and recommendations for application to LCA. Ecol. Indic. 2016, 71, 163-174. [CrossRef]

7. Shimako, A. Contribution to the Development of a Dynamic Life Cycle Assessment Method; INSA de Toulouse: Toulouse, France, 2017.

8. Shimako, A.H.; Tiruta-Barna, L.; Bisinella de Faria, A.B.; Ahmadi, A.; Spérandio, M. Sensitivity analysis of temporal parameters in a dynamic LCA framework. Sci. Total Environ. 2018, 624, 1250-1262. [CrossRef]

9. Seshadri, A.K. Fast-slow climate dynamics and peak global warming. Clim. Dyn. 2017, 48, $2235-2253$. [CrossRef]

10. Intergovernmental Panel on Climate Change. Drivers, Trends and Mitigation; IPCC: Cambridge, UK; New York, NY, USA, 2014.

11. EC (European Commission). Green Paper: A 2030 Framework for Climate and Energy Policies COM (2013) 169; EC: Brussels, Belgium, 2013.

12. EC (European Commission). 23/24 October 2014—Conclusions, EUCO 169/14; EC: Brussels, Belgium, 2014.

13. Leip, A.; Weiss, F.; Wassenaar, T.; Perez, I.; Fellmann, T.; Loudjani, P.; Tubiello, F.; Grandgirard, D.; Monni, S.; Biala, K. Evaluation of the Livestock Sector's Contribution to the EU Greenhouse Gas Emissions_Final Report; EC: Brussels, Belgium, 2010.

14. Domínguez, I.P.; Fellmann, T.; Witzke, H.-P.; Jansson, T.; Oudendag, D.; Gocht, A.; Verhoog, D. Agricultural GHG Emissions in the EU: An Exploratory Economic Assessment of Mitigation Policy Options; EC: Brussels, Belgium, 2012.

15. Myhre, G.; Shindell, D.; Breéon, F.-M.; Collins, W.; Fuglestvedt, J.; Huang, J.; Koch, D.; Lamarque, J.-F.; Lee, D.; Mendoza, B.; et al. Anthropogenic and Natural Radiative Forcing, Supplementary Material. In Climate Change 2013: The Physical Science Basis. Contribution of Working Group I to the Fifth Assessment Report of the Intergovernmental Panel on Climate, Change; Stocker, T.F., Qin, D., Plattner, G.-K., Tignor, M., Allen, S.K., Boschung, J., Nauels, A., Xia, Y., Bex, V., Midgley, P.M., Eds.; Cambridge University Press: Cambridge, UK; New York, NY, USA, 2013.

16. IPCC. Guidelines for National Greenhouse Gas Inventories; Eggleston, H.S., Buendia, L., Miwa, K., Ngara, T., Tanabe, K., Eds.; IGES: Kanagawa, Japan, 2006.

17. Houghton, J.T.; Jenkins, G.J.; Ephraums, J.; IPCC. Climate Change: The IPCC Scientific Assessment; Cambridge University Press: Cambridge, UK, 1990.

18. Skytt, T.; Nielsen, S.N.; Jonsson, B.G. Global warming potential and absolute global temperature change potential from carbon dioxide and methane fluxes as indicators of regional sustainability-A case study of Jämtland, Sweden. Ecol. Indic. 2020, 110, 105831. [CrossRef] 
19. Shine, K.P. The global warming potential-the need for an interdisciplinary retrial. Clim. Chang. 2009, 96, 467-472. [CrossRef]

20. Peters, G.P.; Aamaas, B.; T. Lund, M.; Solli, C.; Fuglestvedt, J.S. Alternative "global warming" metrics in life cycle assessment: A case study with existing transportation data. Environ. Sci. Technol. 2011, 45, 8633-8641. [CrossRef] [PubMed]

21. Ledgard, S.; Reisinger, A. Implications of alternative greenhouse gas metrics for life cycle assessments of livestock food products. In Proceedings of the 9th International Conference on Life Cycle Assessment in the Agri-Food Sector (LCA Food 2014), San Francisco, CA, USA, 8-10 October 2014.

22. Joos, F.; Roth, R.; Fuglestvedt, J.S.; Peters, G.P.; Enting, I.G.; Von Bloh, W.; Brovkin, V.; Burke, E.J.; Eby, M.; Edwards, N.R.; et al. Carbon dioxide and climate impulse response functions for the computation of greenhouse gas metrics: A multi-model analysis. Atmos. Chem. Phys. 2013, 13, 2793-2825. [CrossRef]

23. Tanaka, K.; Johansson, D.J.A.; O’Neill, B.C.; Fuglestvedt, J.S. Emission metrics under the $2{ }^{\circ} \mathrm{C}$ climate stabilization target. Clim. Chang. 2013, 117, 933-941. [CrossRef]

24. Petersen, B.M.; Knudsen, M.T.; Hermansen, J.E.; Halberg, N. An approach to include soil carbon changes in life cycle assessments. J. Clean. Prod. 2013, 52, 217-224. [CrossRef]

25. Fuglestvedt, J.S.; Berntsen, T.K.; Godal, O.; Sausen, R.; Shine, K.P.; Skodvin, T. Metrics of climate change: Assessing radiative forcing and emission indices. Clim. Chang. 2003, 58, 267-331. [CrossRef]

26. Levasseur, A.; Lesage, P.; Margni, M.; Deschěnes, L.; Samson, R. Considering time in LCA: Dynamic LCA and its application to global warming impact assessments. Environ. Sci. Technol. 2010, 44, 3169-3174. [CrossRef]

27. Olivié, D.J.L.; Peters, G.P. Variation in emission metrics due to variation in $\mathrm{CO} 2$ and temperature impulse response functions. Earth Syst. Dyn. 2013, 4, 267-286. [CrossRef]

28. Aamaas, B.; Berntsen, T.K.; Fuglestvedt, J.S.; Shine, K.P.; Collins, W.J. Regional temperature change potentials for short-lived climate forcers based on radiative forcing from multiple models. Atmos. Chem. Phys. 2017, 17, 10795-10809. [CrossRef]

29. Olivié, D.J.L.; Peters, G.P. The impact of model variation in $\mathrm{CO} 2$ and temperature impulse response functions on emission metrics. Earth Syst. Dyn. Discuss. 2012, 3, 935-977. [CrossRef]

30. Boucher, O.; Reddy, M.S. Climate trade-off between black carbon and carbon dioxide emissions. Energy Policy 2008, 36, 193-200. [CrossRef]

31. Shine, K.P.; Berntsen, T.K.; Fuglestvedt, J.S.; Skeie, R.B.; Stuber, N. Comparing the climate effect of emissions of short- and long-lived climate agents. Philos. Trans. R. Soc. A Math. Phys. Eng. Sci. 2007, 365, 1903-1914. [CrossRef] [PubMed]

32. Dace, E.; Blumberga, D. How do 28 European Union Member States perform in agricultural greenhouse gas emissions? It depends on what we look at: Application of the multi-criteria analysis. Ecol. Indic. 2016, 71, 352-358. [CrossRef]

33. Rypdal, K.; Berntsen, T.; Fuglestvedt, J.S.; Aunan, K.; Torvanger, A.; Stordal, F.; Pacyna, J.M.; Nygaard, L.P. Tropospheric ozone and aerosols in climate agreements: Scientific and political challenges. Environ. Sci. Policy 2005, 8, 29-43. [CrossRef]

34. Aamaas, B.; Peters, G.P.; Fuglestvedt, J.S. A synthesis of climate-based emission metrics with applications. Earth Syst. Dyn. Discuss. 2012, 3, 871-934. [CrossRef]

35. Jardine, C.N.; Boardman, B.; Osman, A.; Vowles, J.; Palmer, J. Methane UK; The Environmental Change Institute, University of Oxford: Oxford, UK, 2003.

36. Holmes, C.D. Methane Feedback on Atmospheric Chemistry: Methods, Models, and Mechanisms. J. Adv. Model. Earth Syst. 2018, 10, 1087-1099. [CrossRef]

37. United Nations Environment Programme (UNEP); World Meteorological Organization (WMO). Integrated Assessment of Black Carbon and Tropospheric Ozone. Summary for Decision Makers; UNEP: Nairobi, Kenya; WMO: Geneva, Switzerland, 2011.

38. Cherubini, F.; Huijbregts, M.; Kindermann, G.; Van Zelm, R.; Van Der Velde, M.; Stadler, K.; Strømman, A.H. Global spatially explicit CO2 emission metrics for forest bioenergy. Sci. Rep. 2016, 9, 20186. [CrossRef] [PubMed]

(C) 2020 by the authors. Licensee MDPI, Basel, Switzerland. This article is an open access article distributed under the terms and conditions of the Creative Commons Attribution (CC BY) license (http://creativecommons.org/licenses/by/4.0/). 